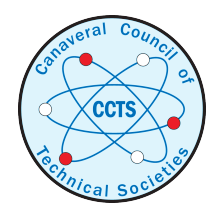

The Space Congress ${ }^{\circledR}$ Proceedings

2018 (45th) The Next Great Steps

Feb 28th, 7:30 AM - 8:30 AM

\title{
Integrating Unmanned Aircraft Systems into the National Airspace System
}

Richard Stansbury Ph.D.

Associate Professor of Computer Science and Computer Engineering at Embry-Riddle Aeronautical University, stansbur@erau.edu

John Robbins Ph.D.

Associate Professor and Program Coordinator for the Bachelor of Science in Unmanned Aircraft Systems at Embry-Riddle Aeronautical University, robbinsj@erau.edu

Follow this and additional works at: https://commons.erau.edu/space-congress-proceedings

\section{Scholarly Commons Citation}

Stansbury, Richard Ph.D. and Robbins, John Ph.D., "Integrating Unmanned Aircraft Systems into the National Airspace System" (2018). The Space Congress ${ }^{\circledR}$ Proceedings. 8.

https://commons.erau.edu/space-congress-proceedings/proceedings-2018-45th/feb-28-2018/8

This Event is brought to you for free and open access by the Conferences at Scholarly Commons. It has been accepted for inclusion in The Space Congress ${ }^{\circledR}$

Proceedings by an authorized administrator of Scholarly Commons. For more information, please contact commons@erau.edu.

EMBRYRIDDLE Aeronautical University SCHOLARLY COMMONS 


\section{Overview}

- Industry Overview

- Systems Overview

- $\quad$ FAR Part 107

- Recent News

- UAS Applications

- UAS Research toward Integration

- Questions

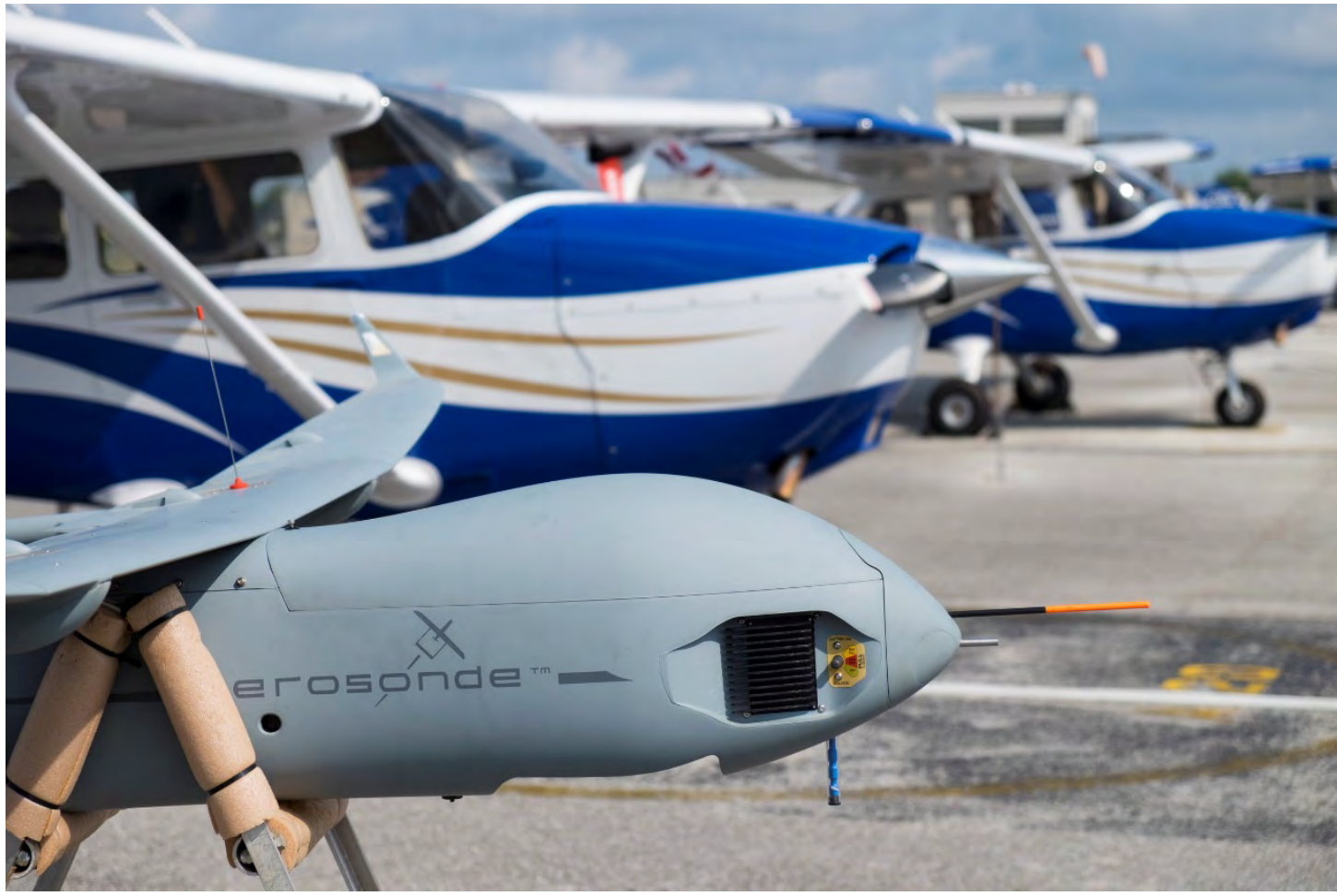




\section{Flight Line and Lab Facilities}
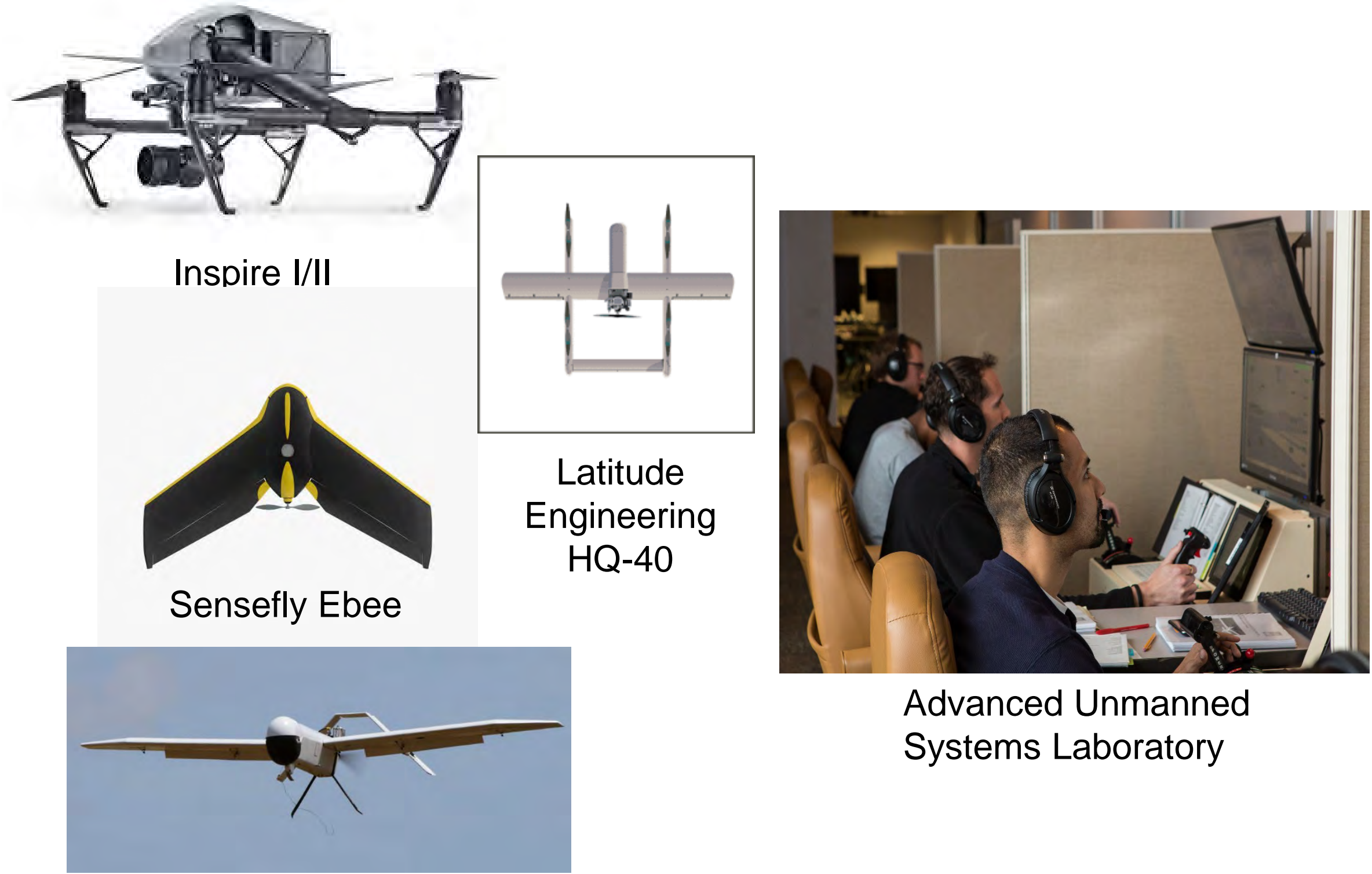

Advanced Unmanned Systems Laboratory

Martin UAV Superbat 


\section{- What is it?}

- UAS, UAVs, RPAs

- Drones

- RC aircraft models

- System of systems

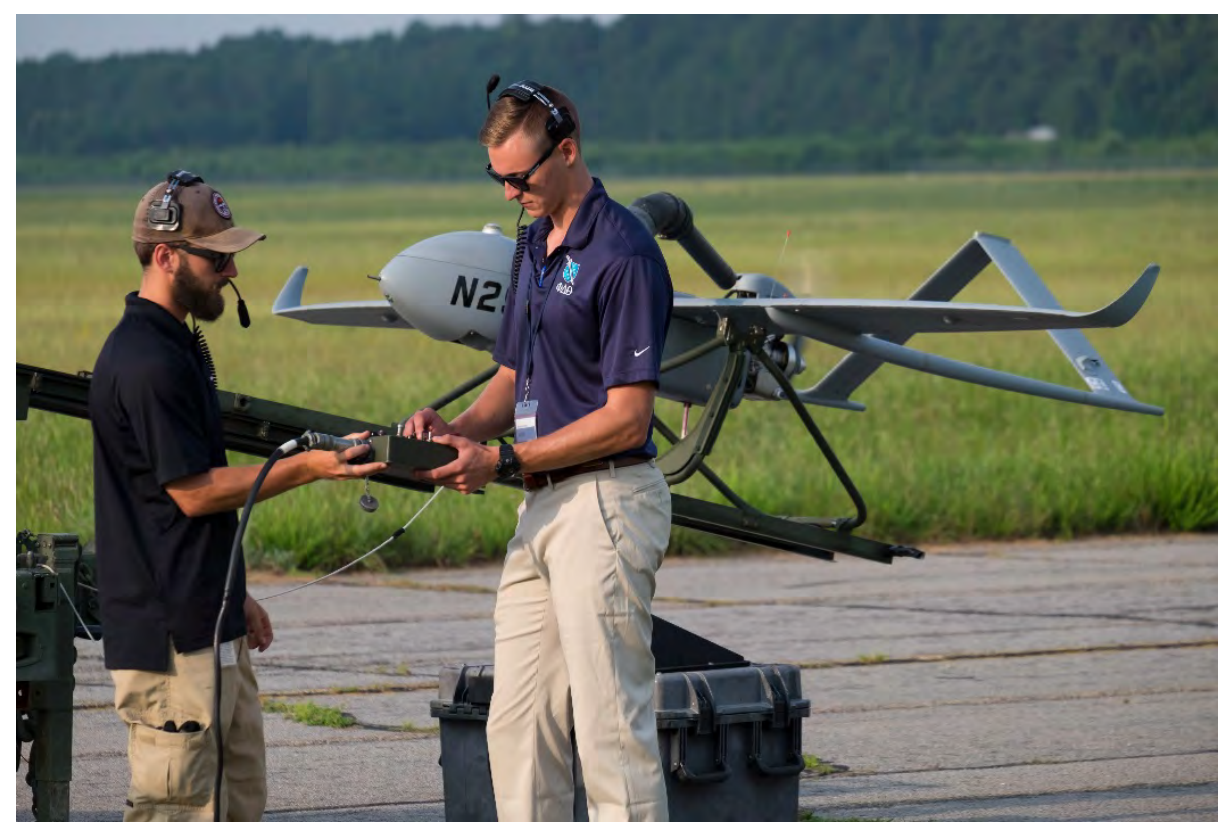

- Tactical ISR

- Miniaturization of Technology

- Availability

- Application

- Increased educational opportunities 


\section{UAS Classification}
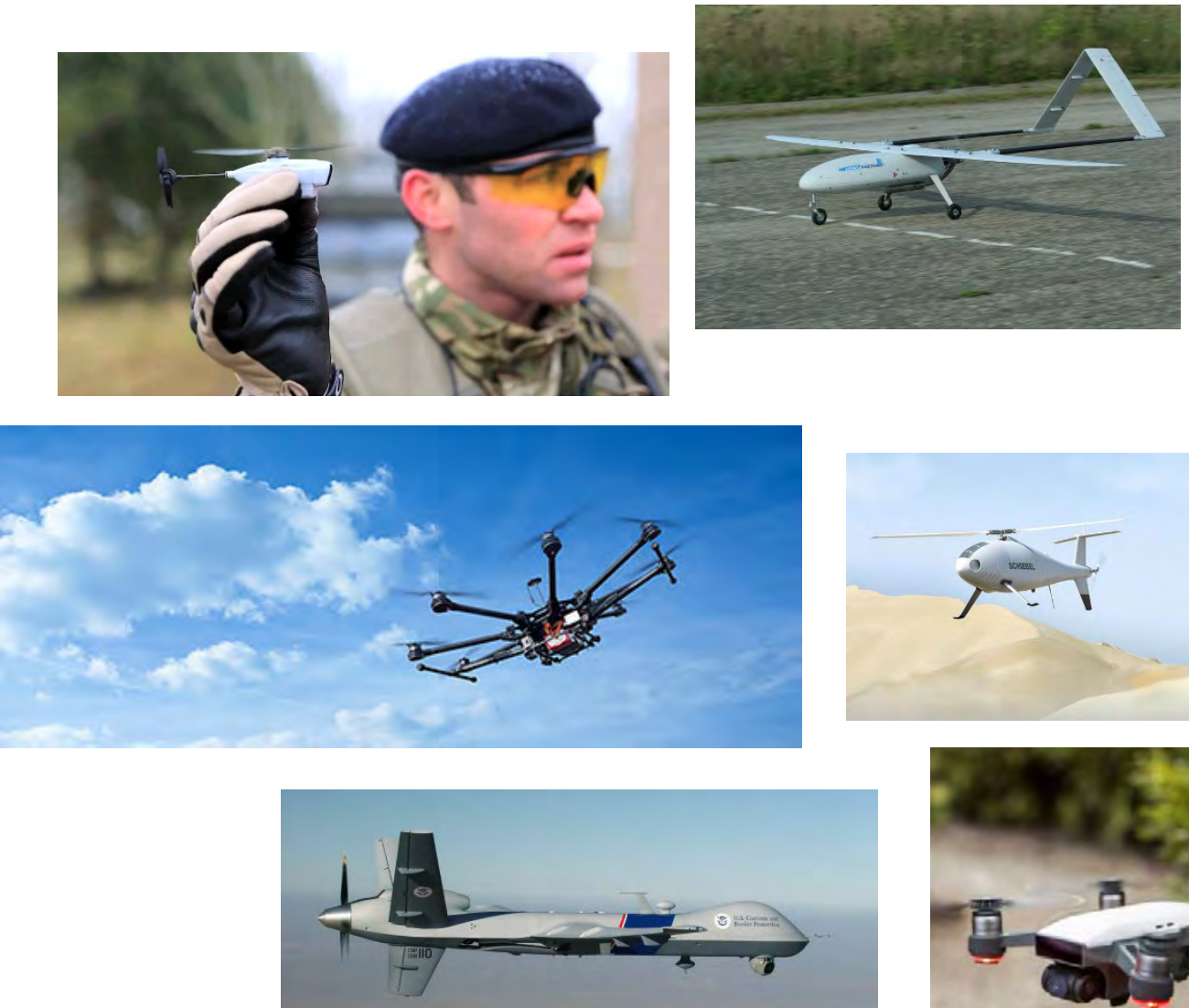

$$
y=-1
$$

䀠 $\overline{1}$
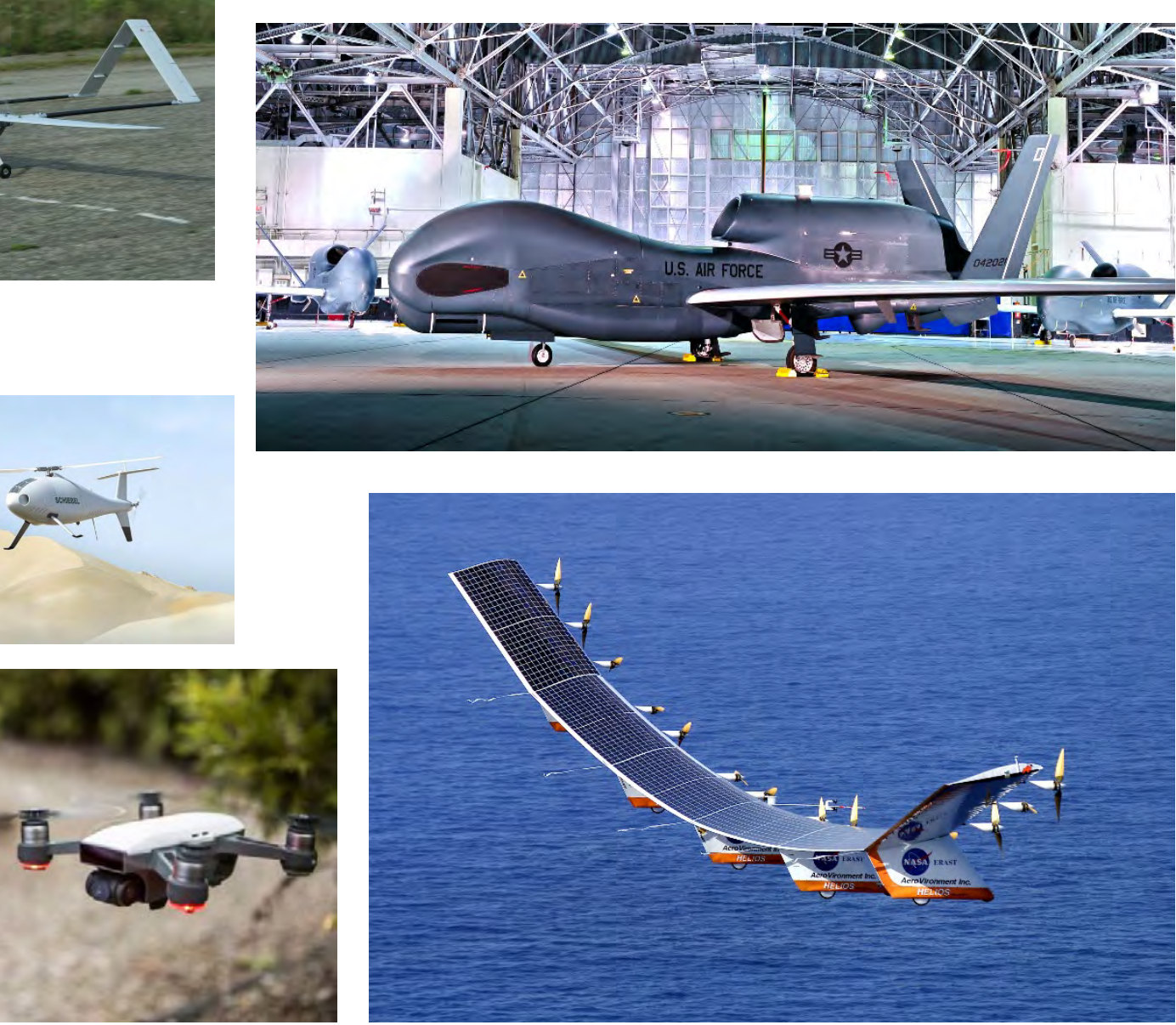


\section{UAS Design}

Vertical Takeoff or Landing

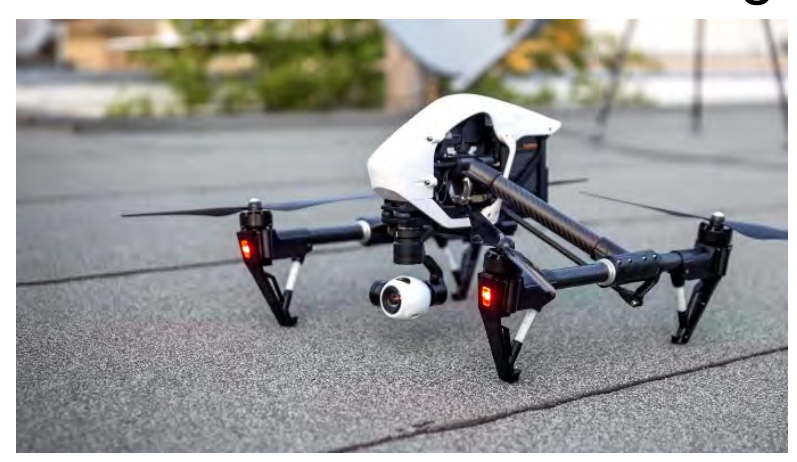

Hybrid

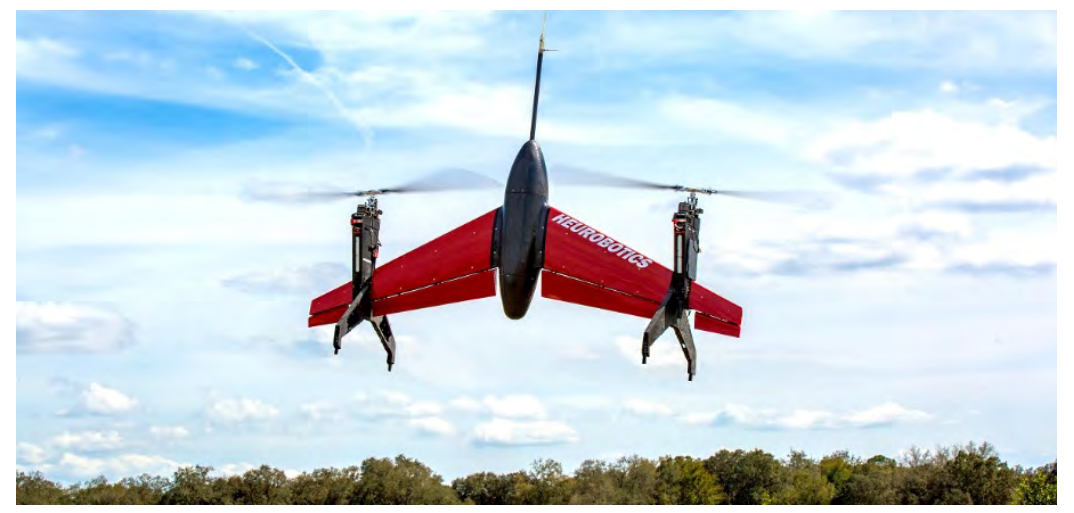

Fixed-Wing

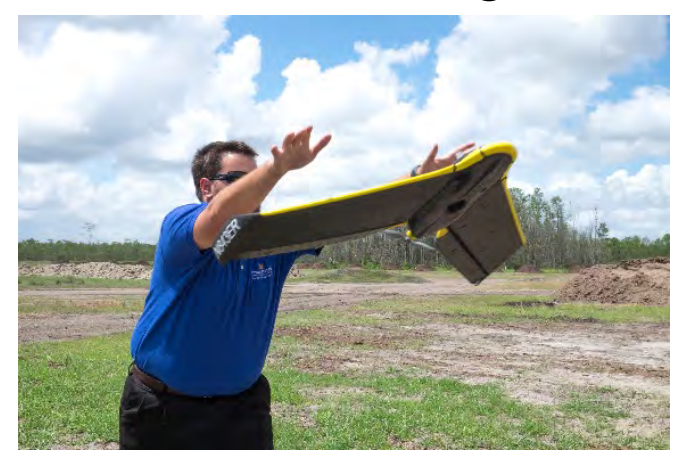

Lighter than Air

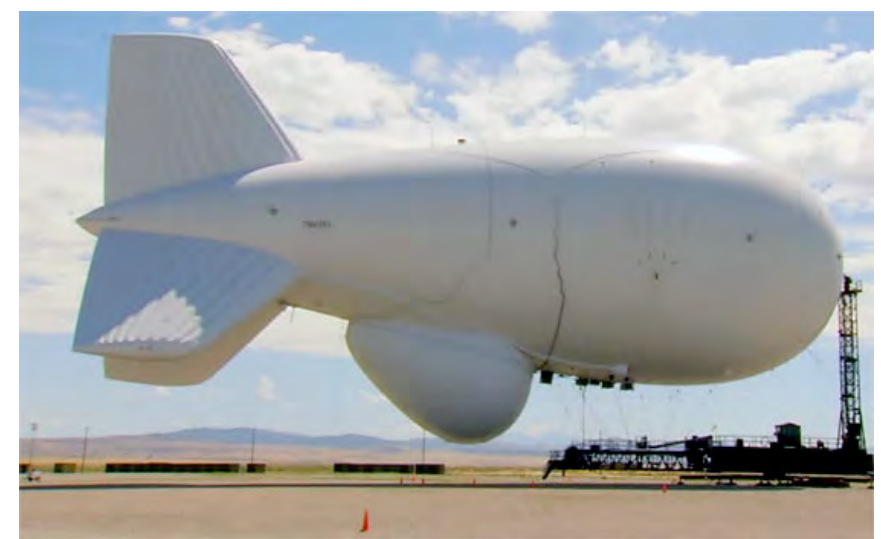




\section{UAS Design}

Systems Architecture

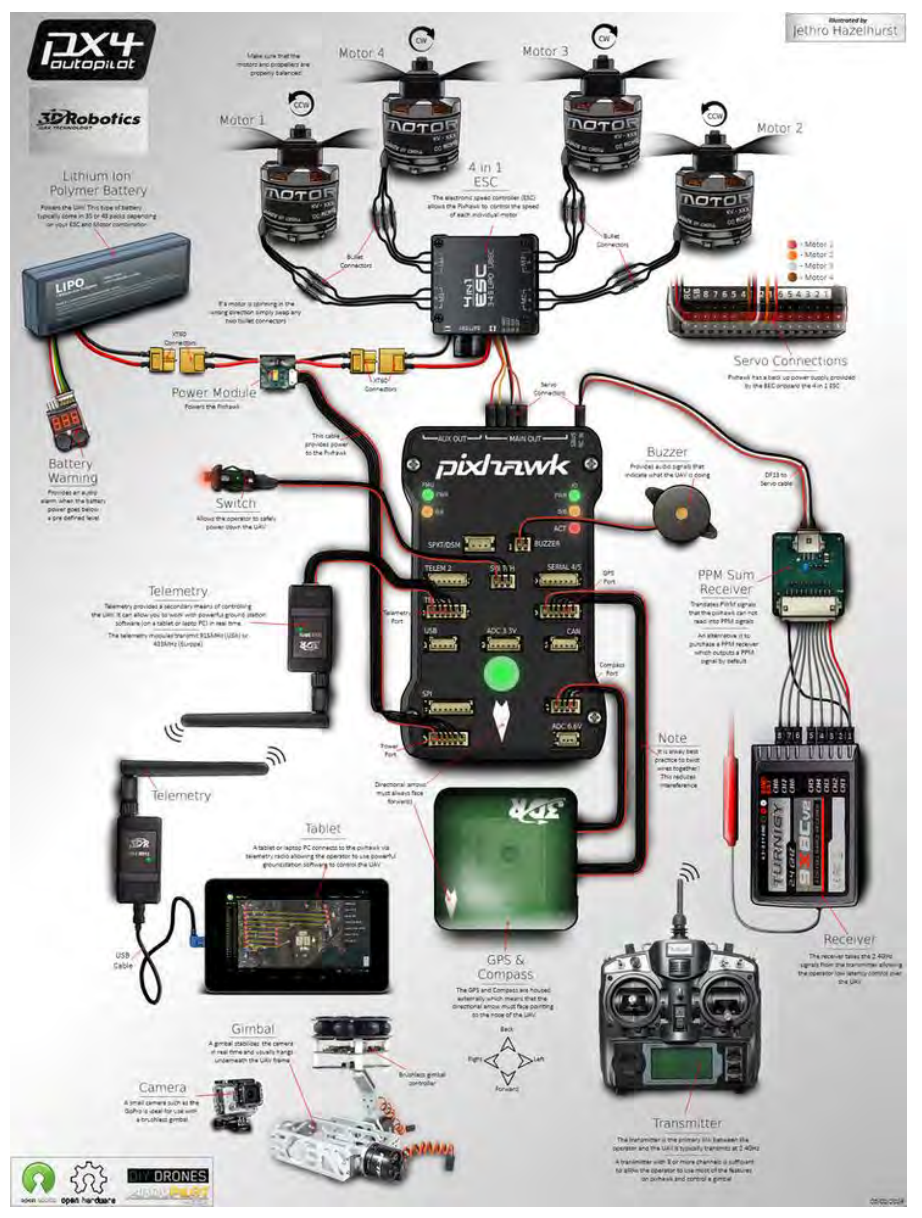




\section{UAS Integration}

- What are the issues with integration?
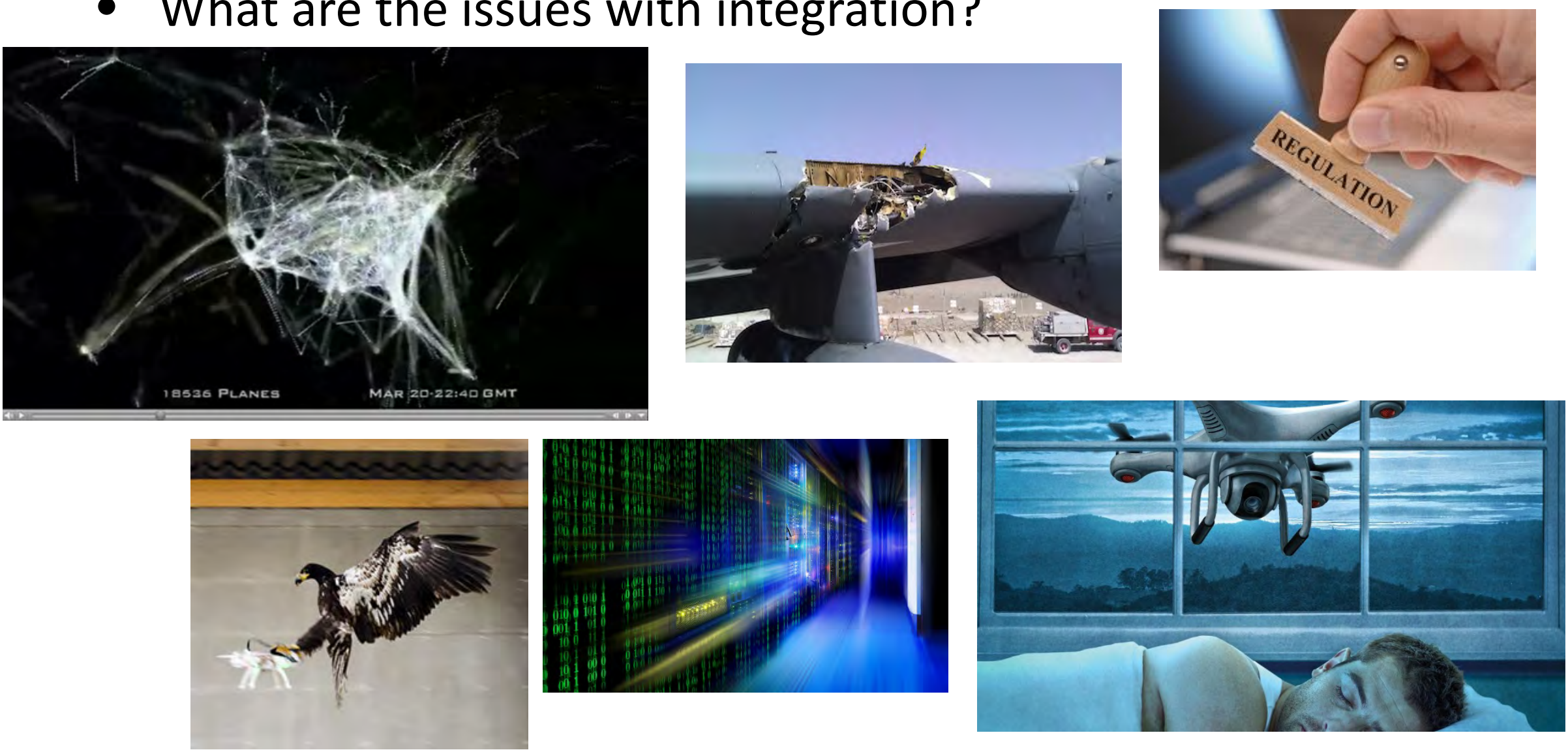


\section{State of Industry}

- $\quad$ Steady demand for government, commercial, and hobbyist use of UAS into the NAS

- 2012 - FAA Reauthorization and Modernization Act called for the integration of UAS into the NAS by 2015

- 2015

- NPRM Small UAS Rules

- ASSURE FAA Center of Excellence for UAS launched

- 2016

- Part 107 - Small UAS Rules released

- microUAS Aviation Rulemaking Committee launched

- FAA's Drone Advisory Committee formed

- $\quad$ No certification or airworthiness standards for UAS
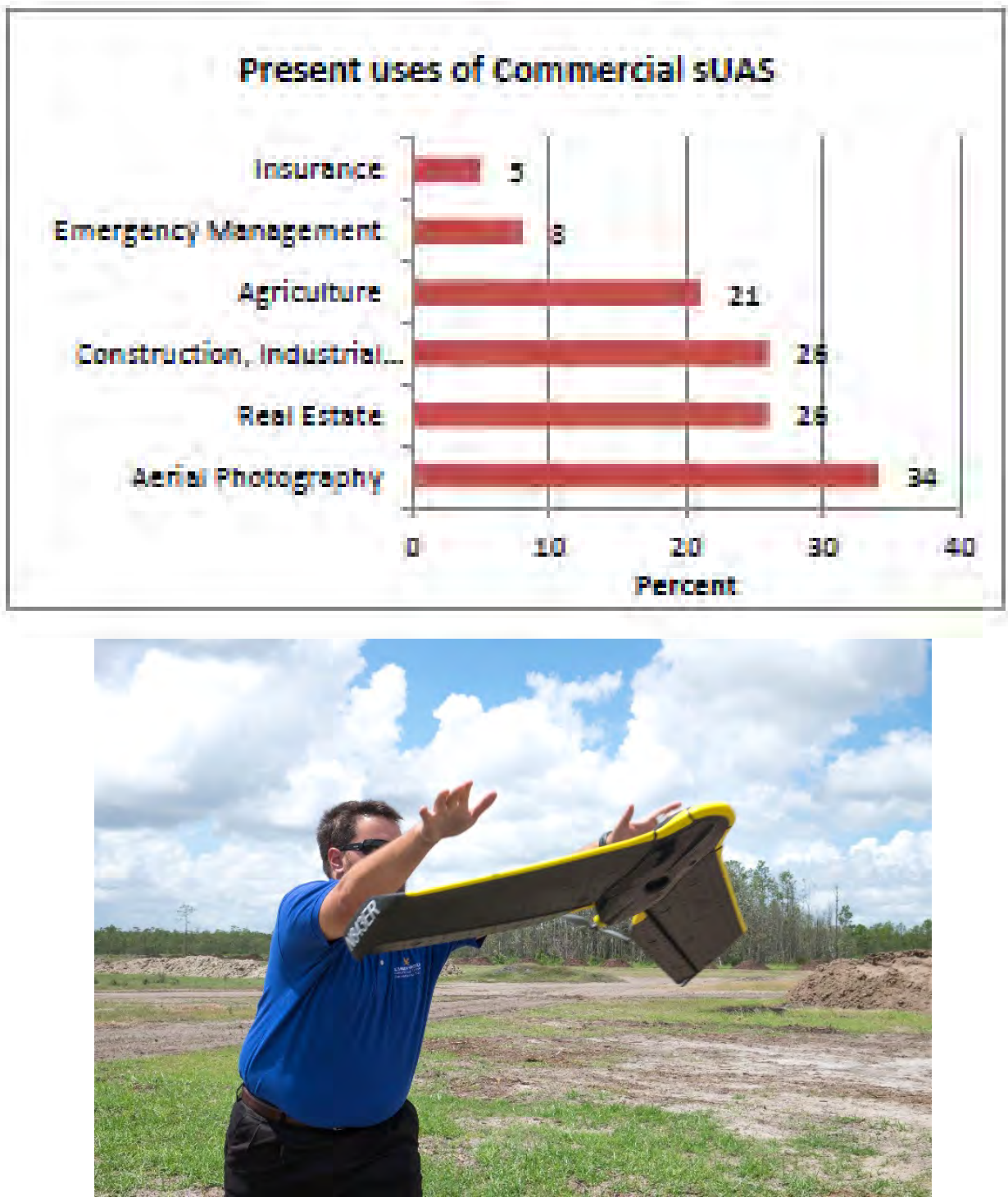


\section{UAS Integration Part 107 Overview}

- $\quad$ RPC required for those operating commercially; Hobby aircraft under Section 336 of Public Law 112-95; AC-91-57 a

- Governing those aircraft weighing less than $55 \mathrm{lbs}$. operating less than $100 \mathrm{mph}$

- No FAA classification scale for those larger than $55 \mathrm{lbs}$.

- Restricted to $400 \mathrm{ft}$. AGL within $400 \mathrm{ft}$. of a structure

- Restricted to Visual Line of Sight Operations (VLOS)

- Many aircraft have the capability to fly Beyond Visual Line of Sight (BLOS)

- Expected rulemaking considering BLOS operations expected soon

- May not operate over any persons not directly participating in the operation, not under a covered structure, and not inside a covered stationary vehicle

- Daylight operations only

- 333 exemptions issued for night operations

- Must always yield right of way to manned aircraft

- Minimum visibility 3 miles from control station

- Ops. in B, C, D, and E airspace allowed with ATC permission - https://www.faa.gov/uas/request_waiver/

- Ops. in Class G allowed with no ATC permissions

- Must be registered in accordance with FAR Part 91.203 (a)(2)

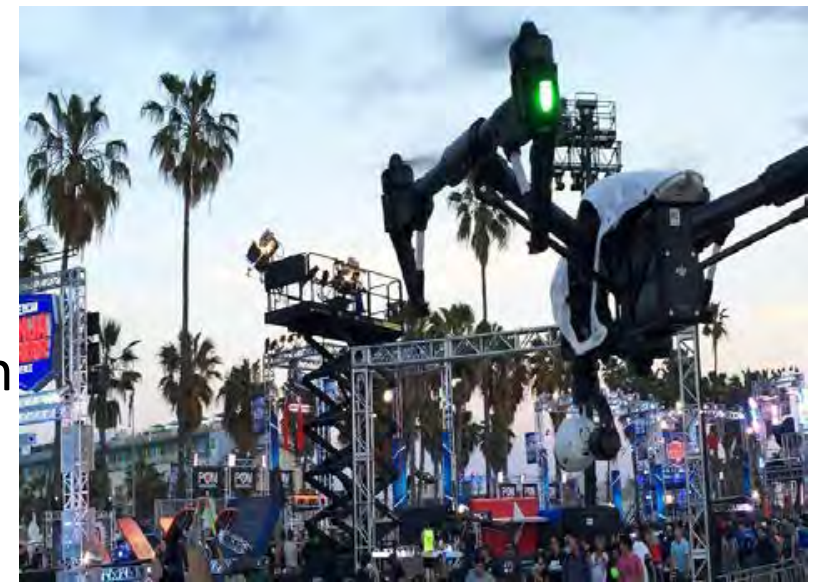




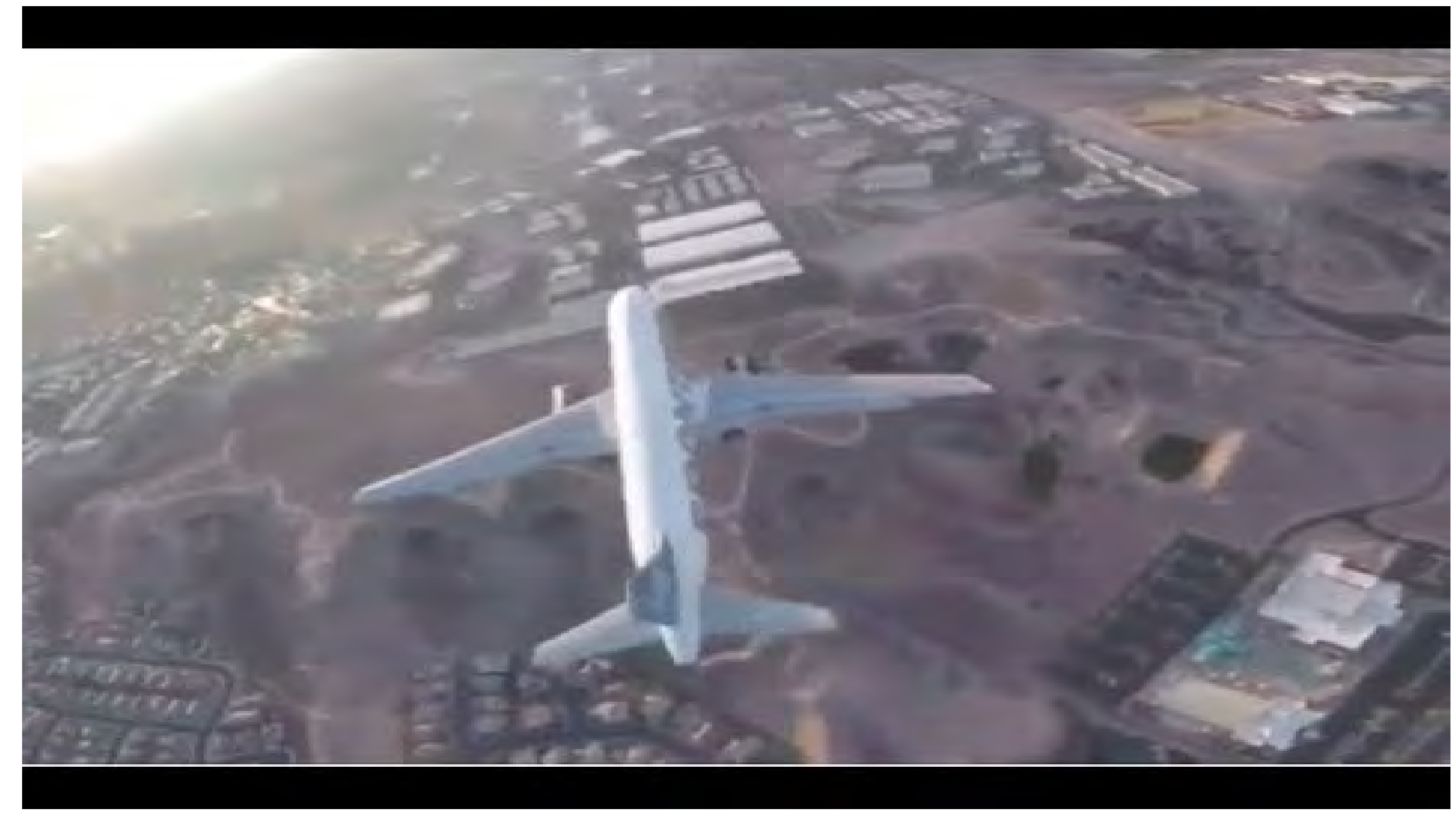




\section{Applications:}

\section{Precision Agriculture}

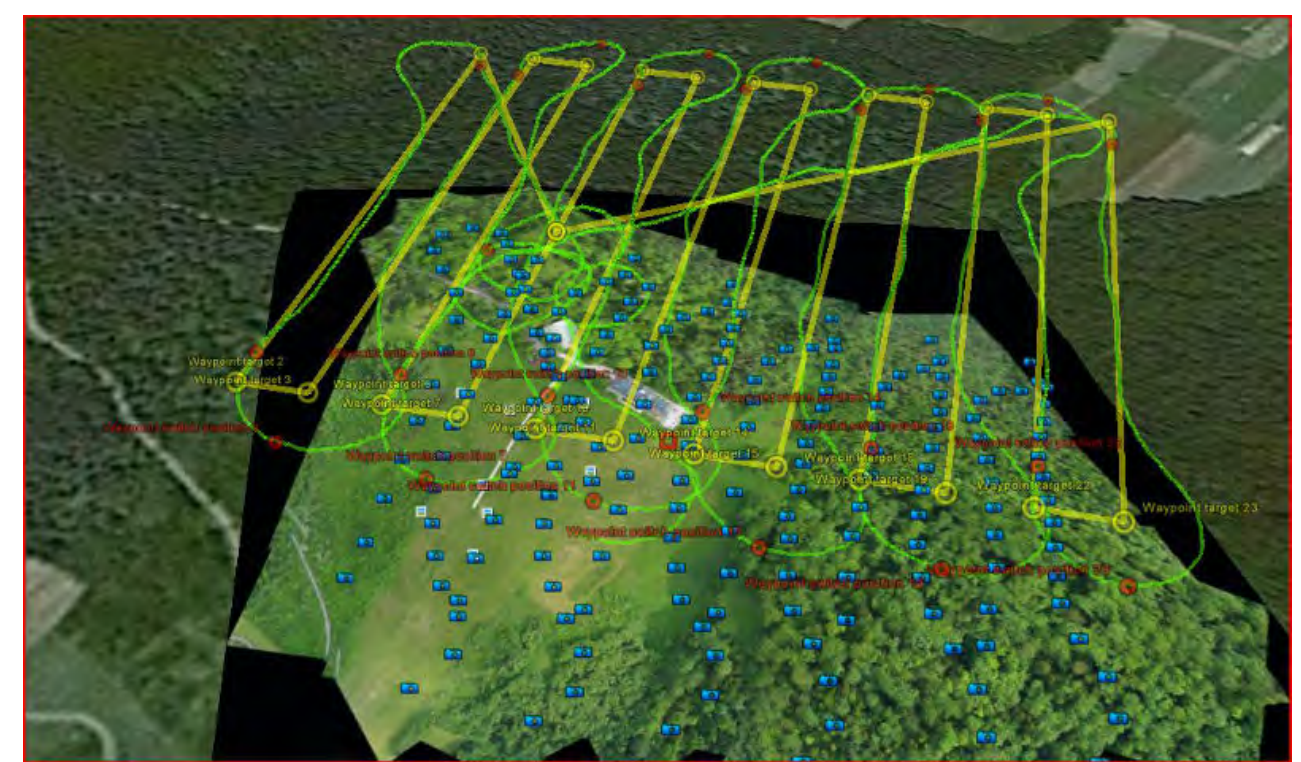

EMBRYAIDDLE Aeronautical University FLORIDA | ARIZONA | WORLDWIDE

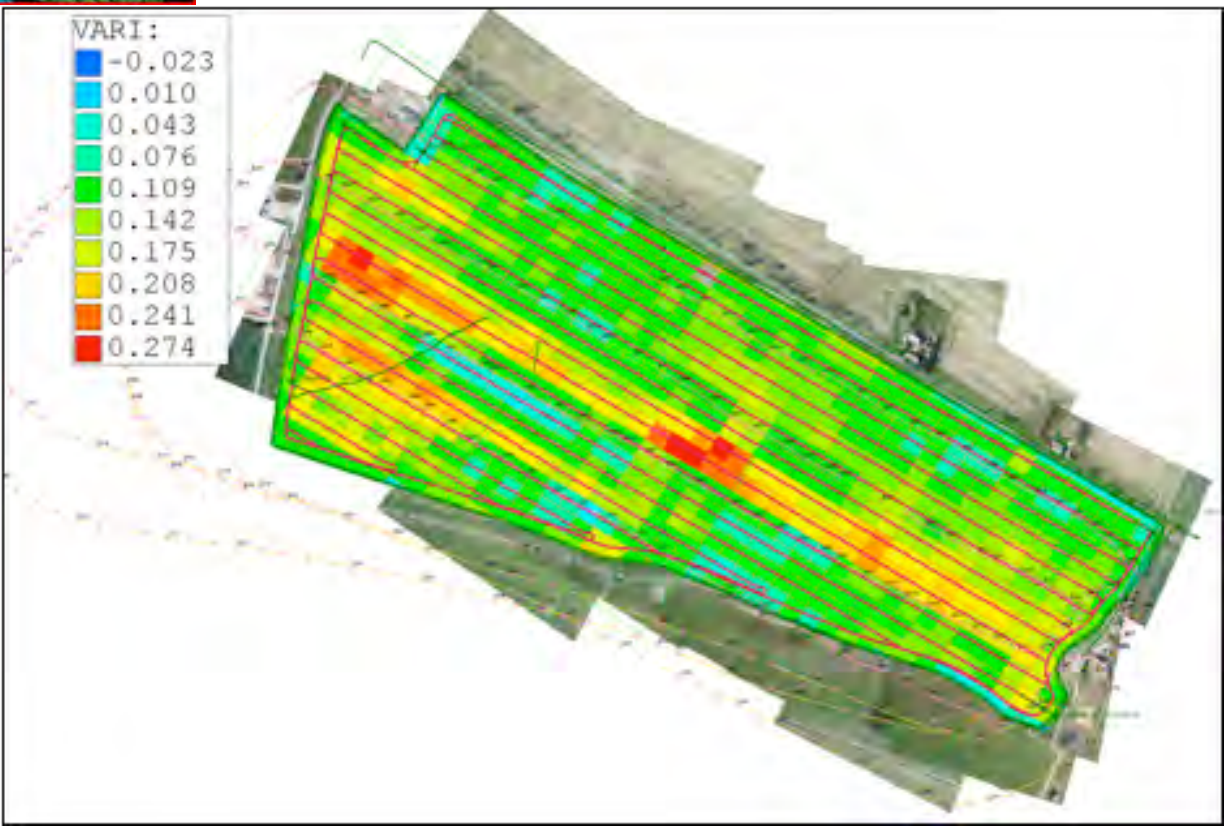



and Public Safety

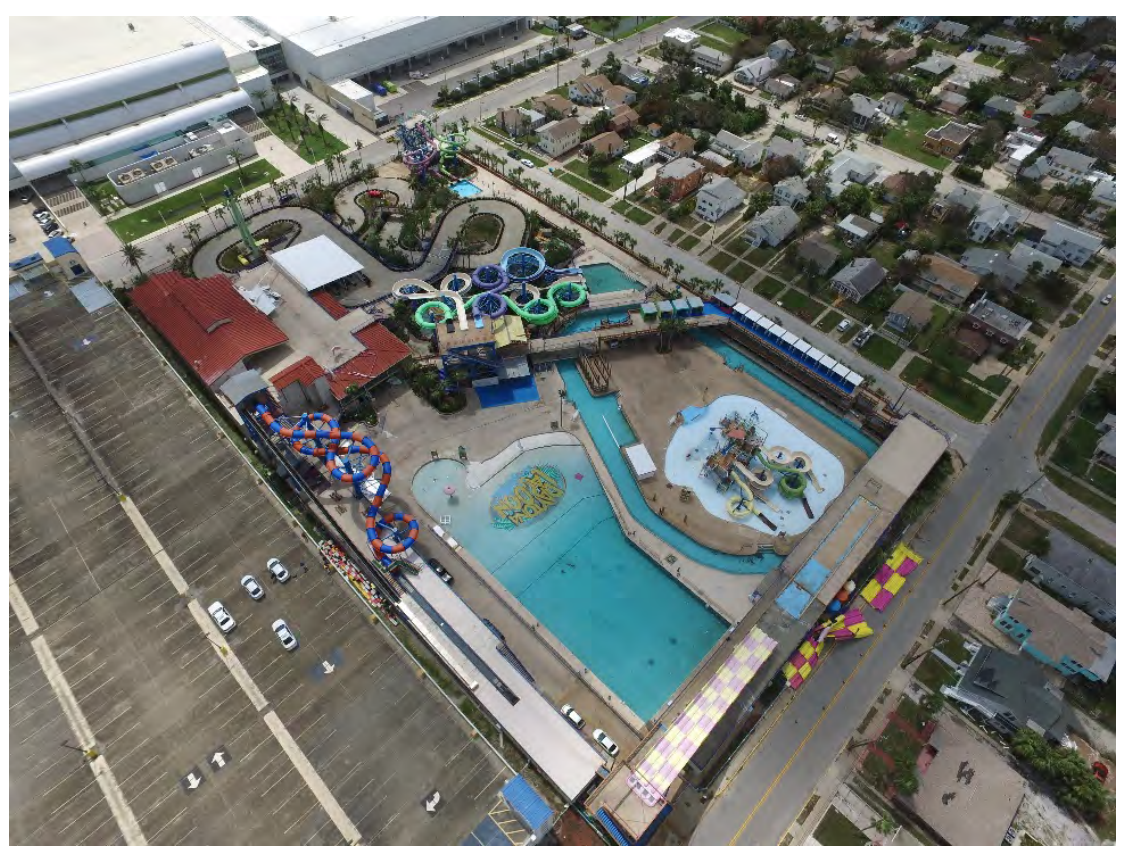

\section{Post Hurricane Irma Damage Assessment}

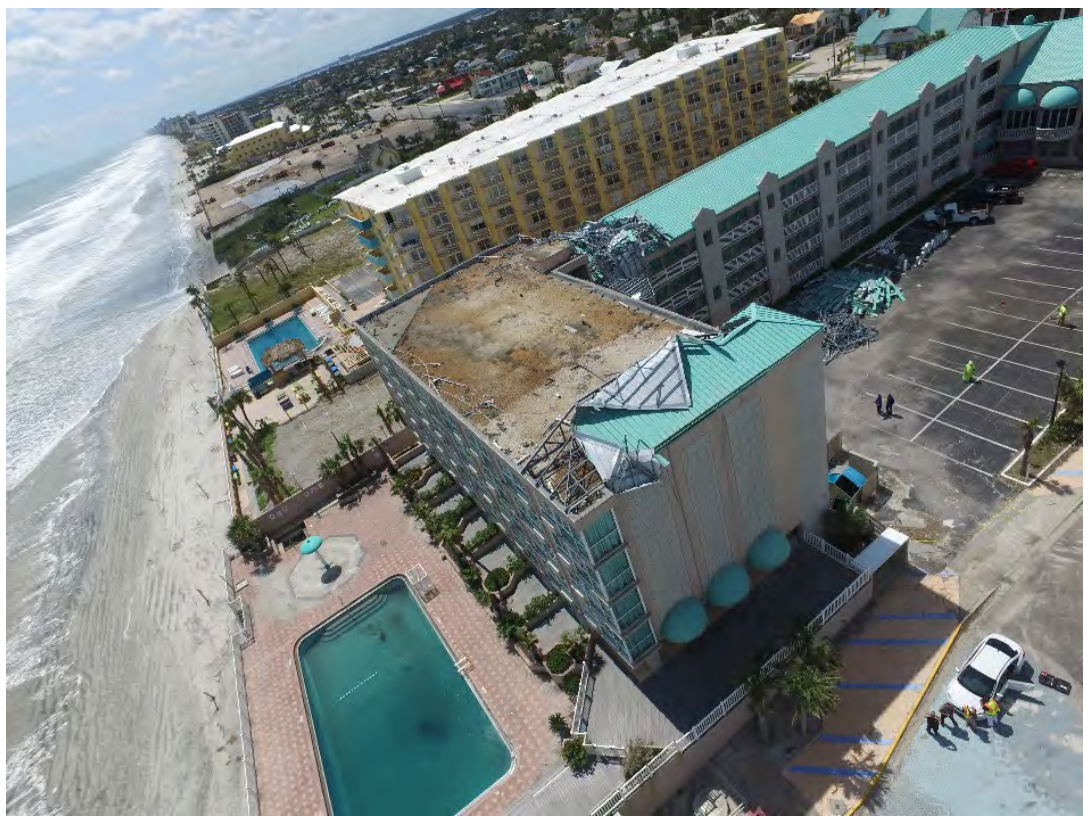




\section{Application:}

\section{Infrastructure Monitoring}

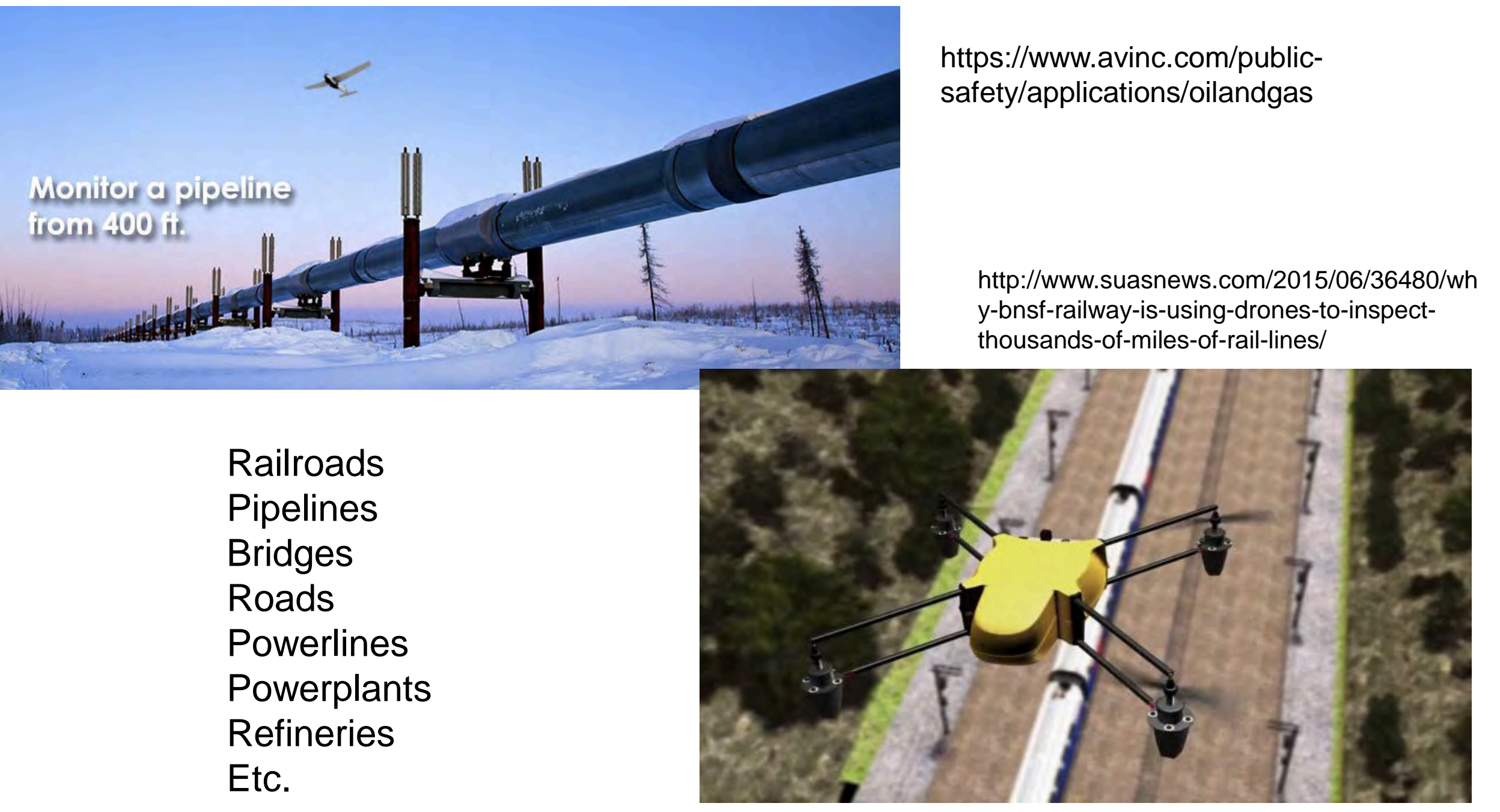




\section{Application:}

\section{Science / Environment}

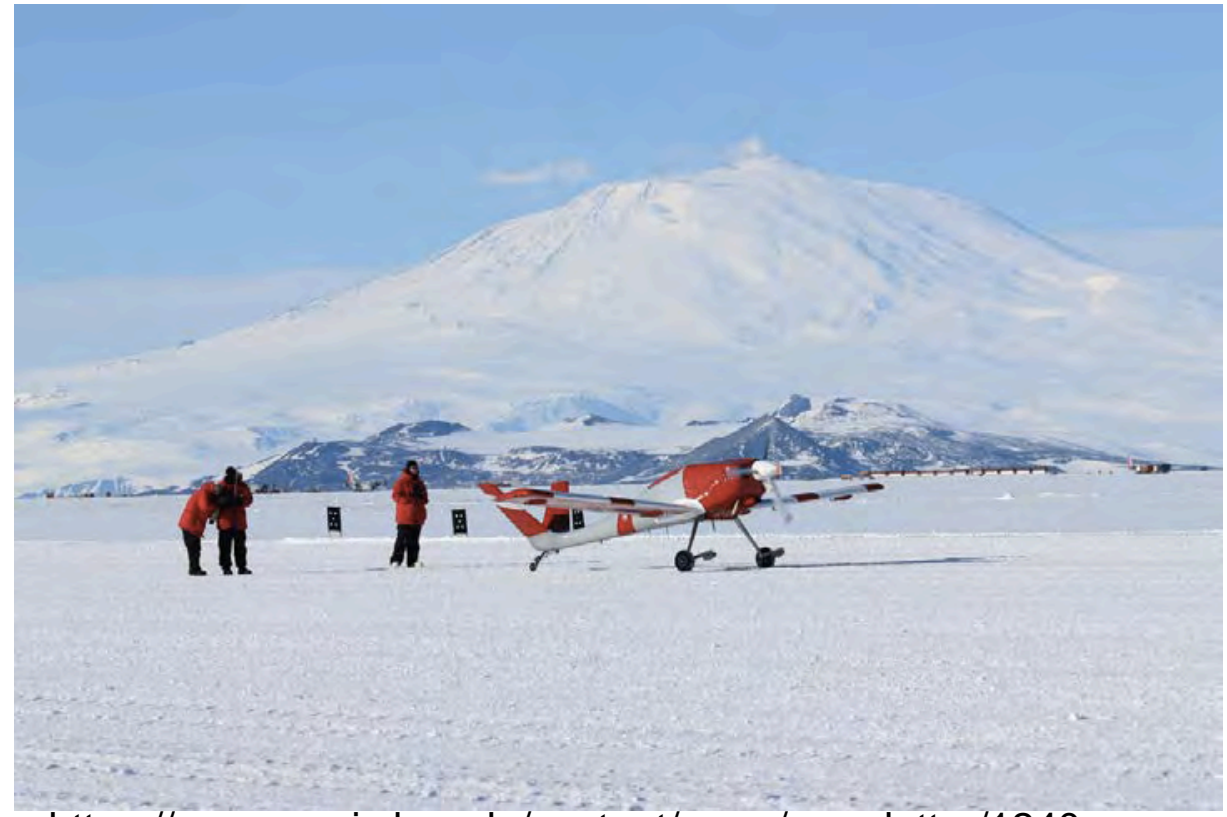

https://www.cresis.ku.edu/content/news/newsletter/1240
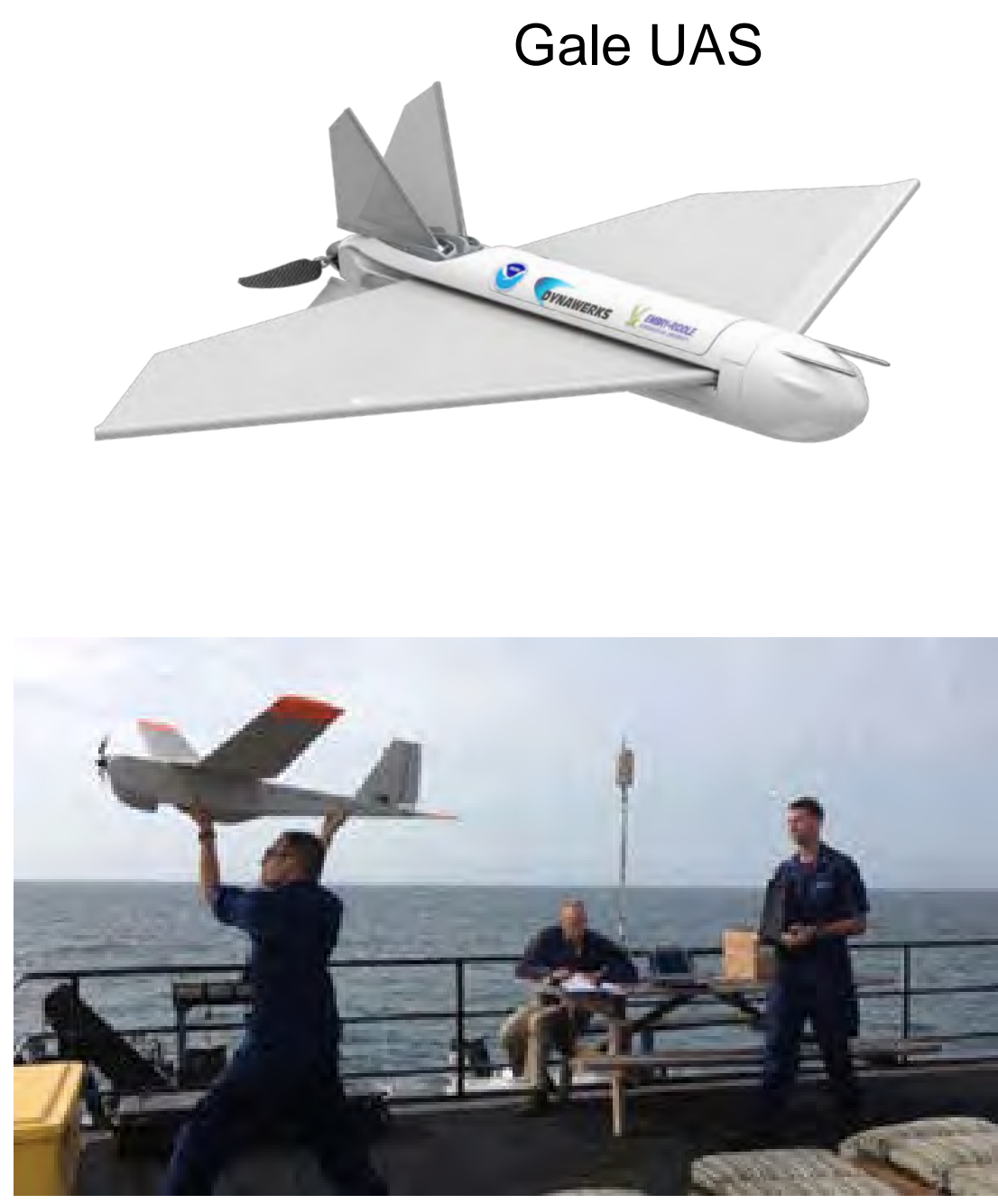

http://www.pifsc.noaa.gov/cruise/ha14

02.php 


\section{Other Applications}

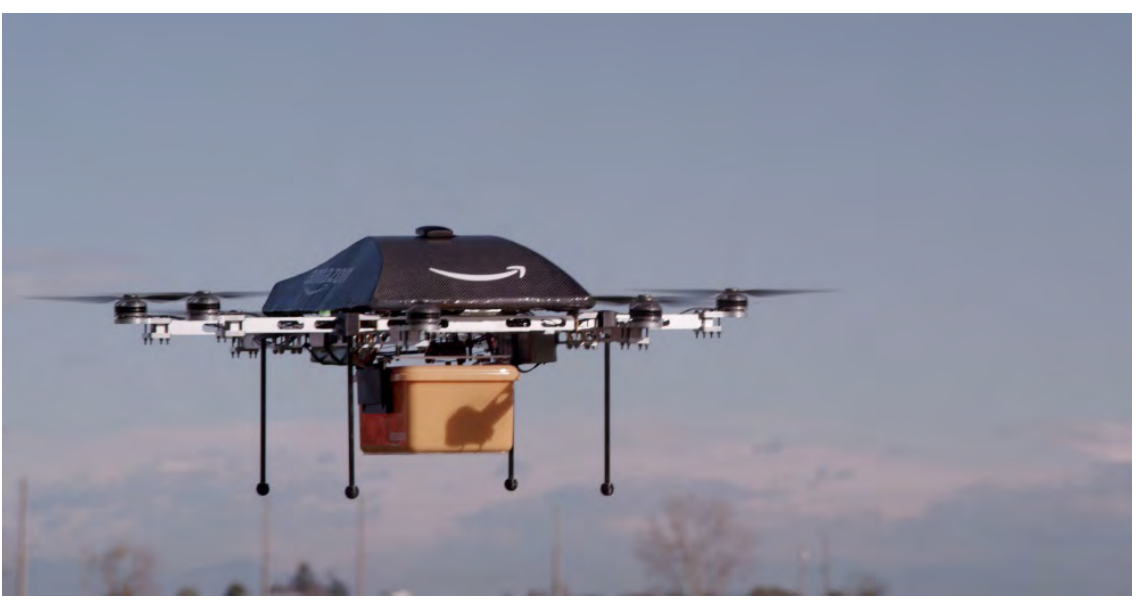

https://www.amazon.com/Amazon-PrimeAir $/ \mathrm{b}$ ?ie $=$ UTF8 \&node $=8037720011$
Delivery

Filmmaking

News photography

Real-estate

Construction survey Insurance assessment

Private detectives / spying

Paparazzi

Humanitarian aid

http://www.uasblog.net/make-real-estate-moreyummily-throw-some-drone-sauce-on-it/

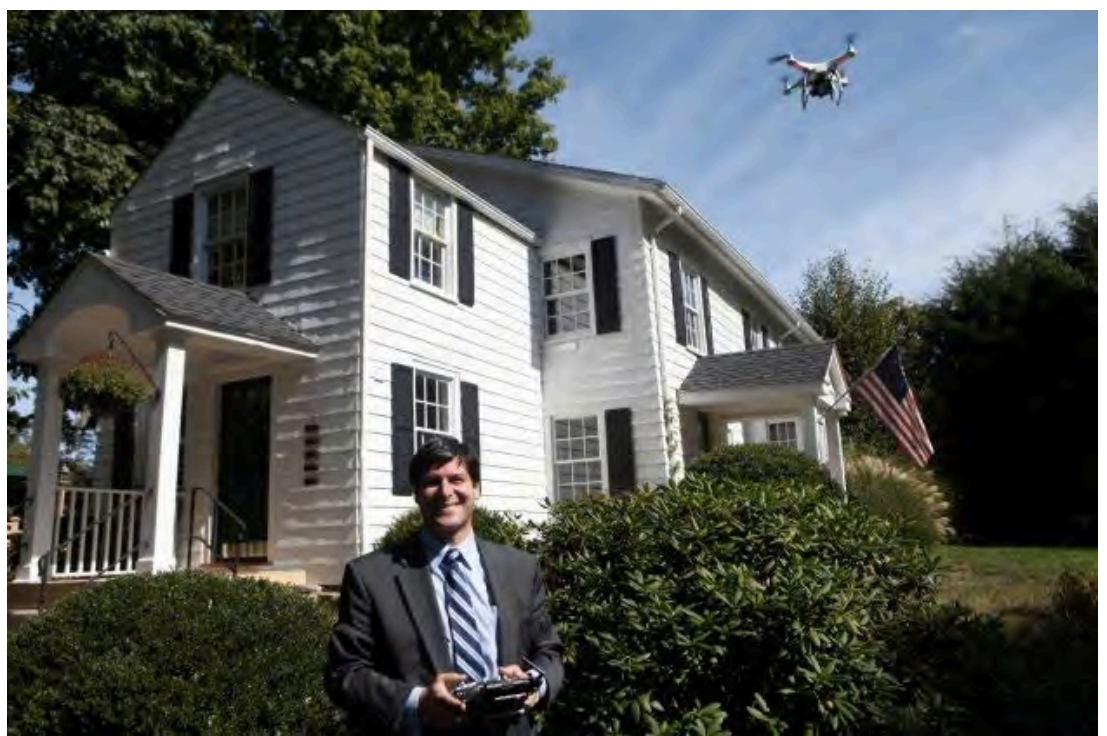




\section{Research Planning}

\section{The Path to Full Integration}
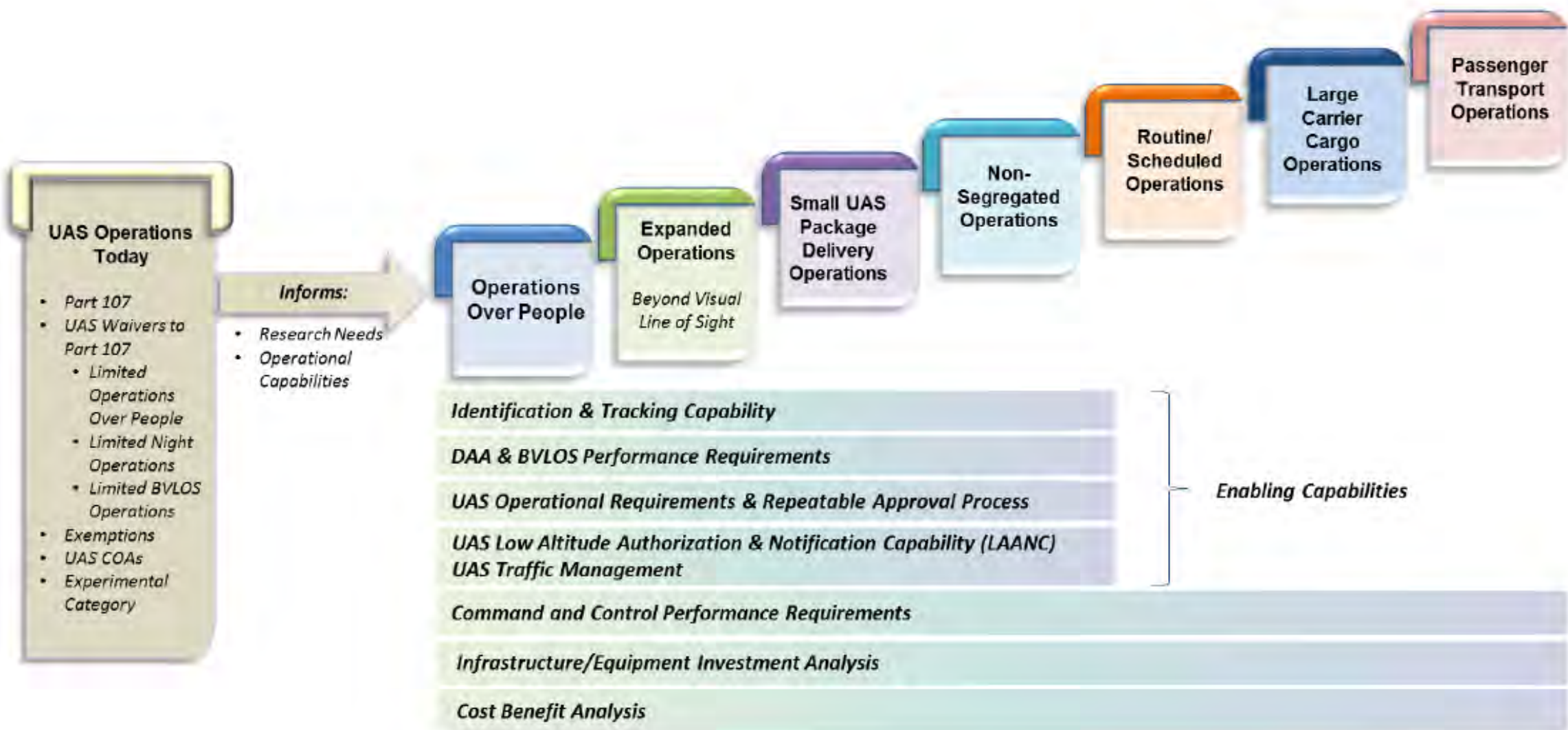

Source: Sabrina Saunders-Hodge, Director UAS Research at FAA UAS Integration Office Briefing at ERAU Symposium for Unmanned and Autonomous Systems, November 30, 2017 


\section{UAS Integration Research Functional Framework}

UAS integration research supports key FAA mission functions to publish regulations, policy, procedures, and guidance material to support safe and efficient UAS operations in the NAS.

Ongoing and planned research activities inform these functional areas.

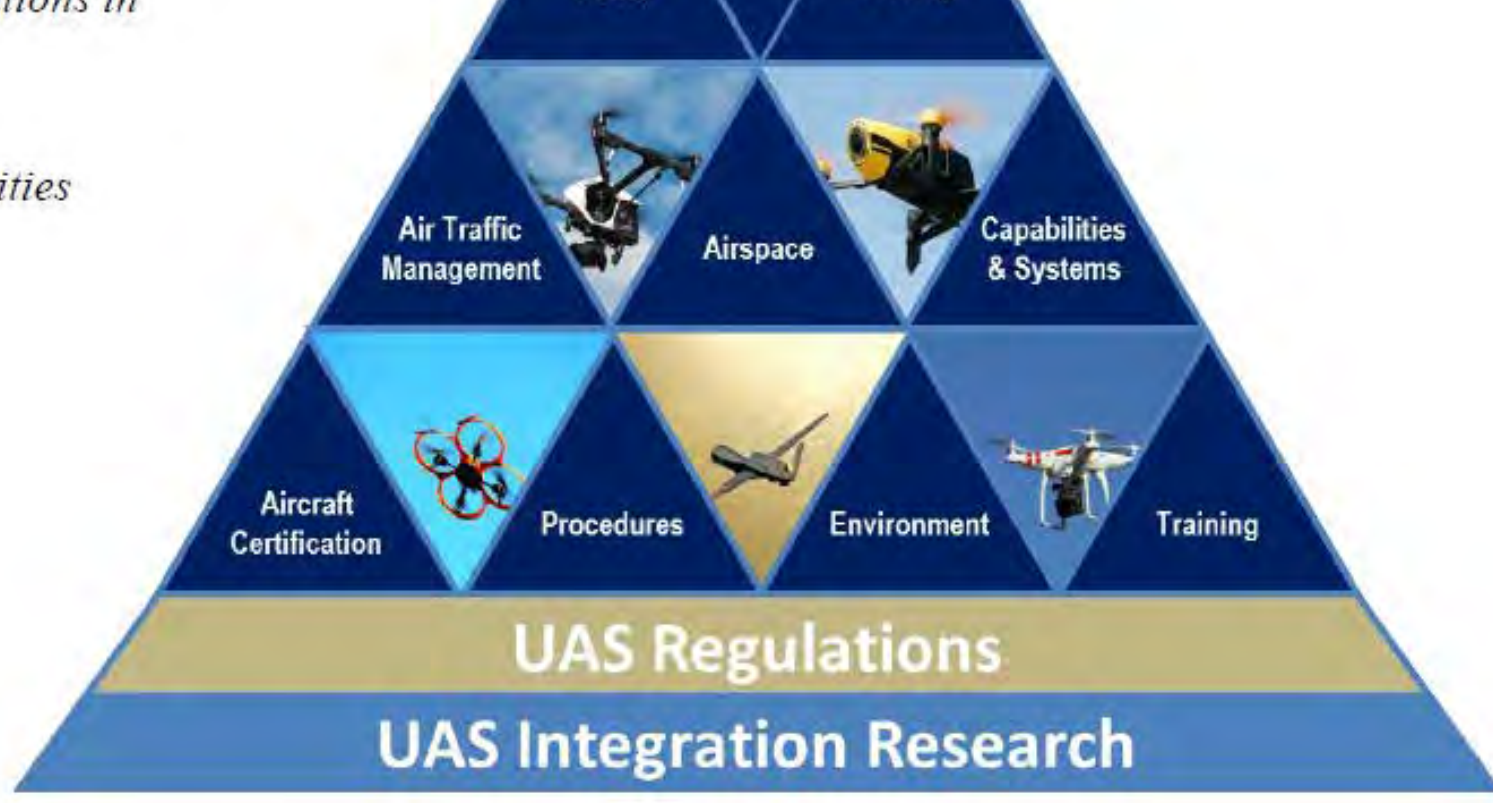

Source: Sabrina Saunders-Hodge, Director UAS Research at FAA UAS Integration Office Briefing at ERAU Symposium for Unmanned and Autonomous Systems, November 30, 2017 


\section{UAS Research Collaboration \& Partnerships}

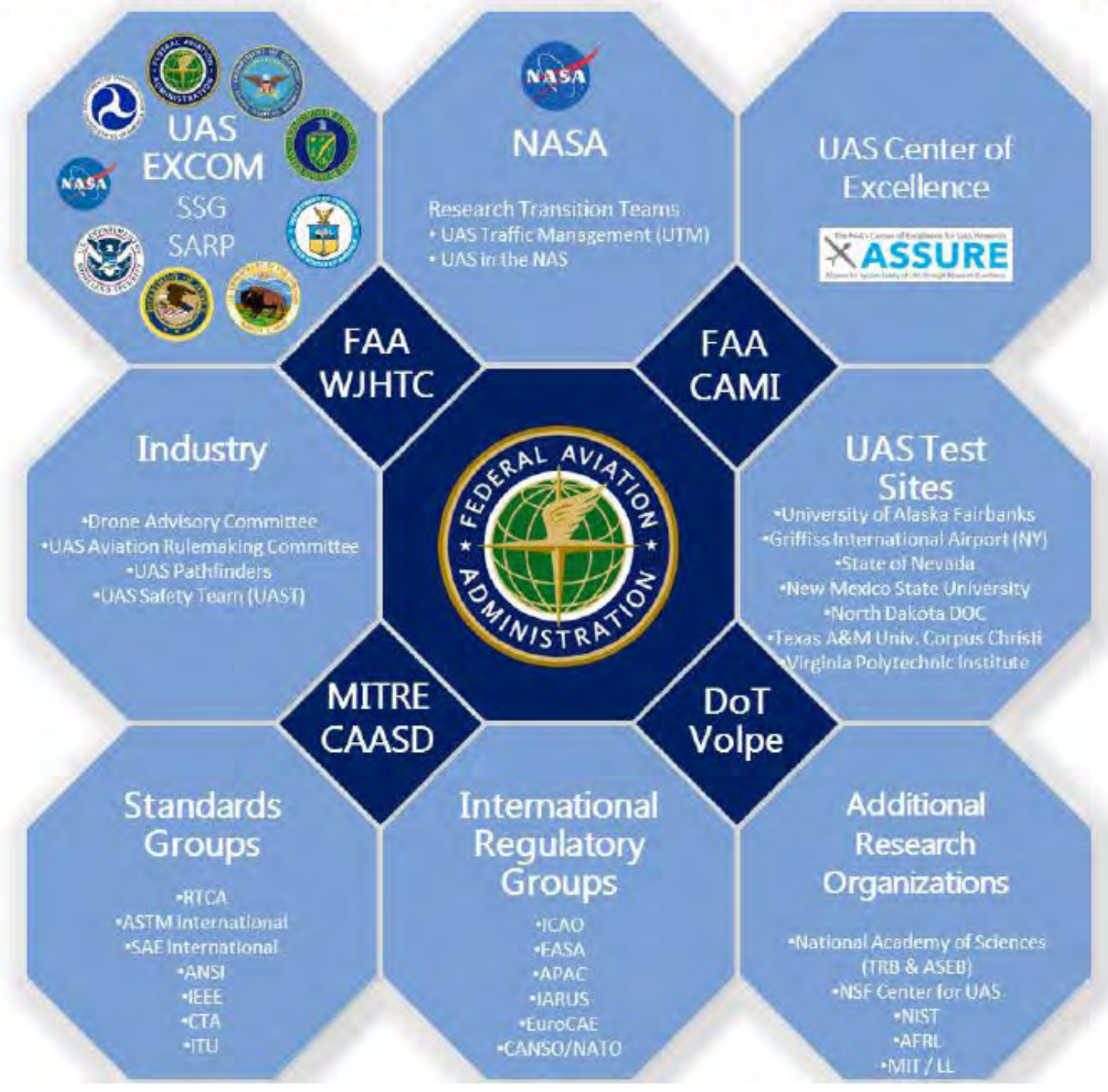

Source: Sabrina Saunders-Hodge, Director UAS Research at FAA UAS Integration Office Briefing at ERAU Symposium for Unmanned and Autonomous Systems, November 30, 2017 
- Long title: The Alliance for System Safety of UAS Through Research Excellence - The Federal Aviation Administration's Center of Excellence for Unmanned Aerial Systems

- Short title: The FAA's Drone Research Center

- COEs are "entities with substantive ties to universities which advance the state of transportation knowledge within a particular aviation area

- FAA William J. Hughes Tech Center manages COEs

- COE's get two funding vehicles

- Grants (mandatory 1-to-1 cost share)

- IDIQ Contracts (cost share negotiable)

- 23 Schools, 100+ companies - big team for a big job! 
$\exists M=3 \mathrm{R}$
Aeronautical University FLORIDA | ARIZONA | WORLDWIDE

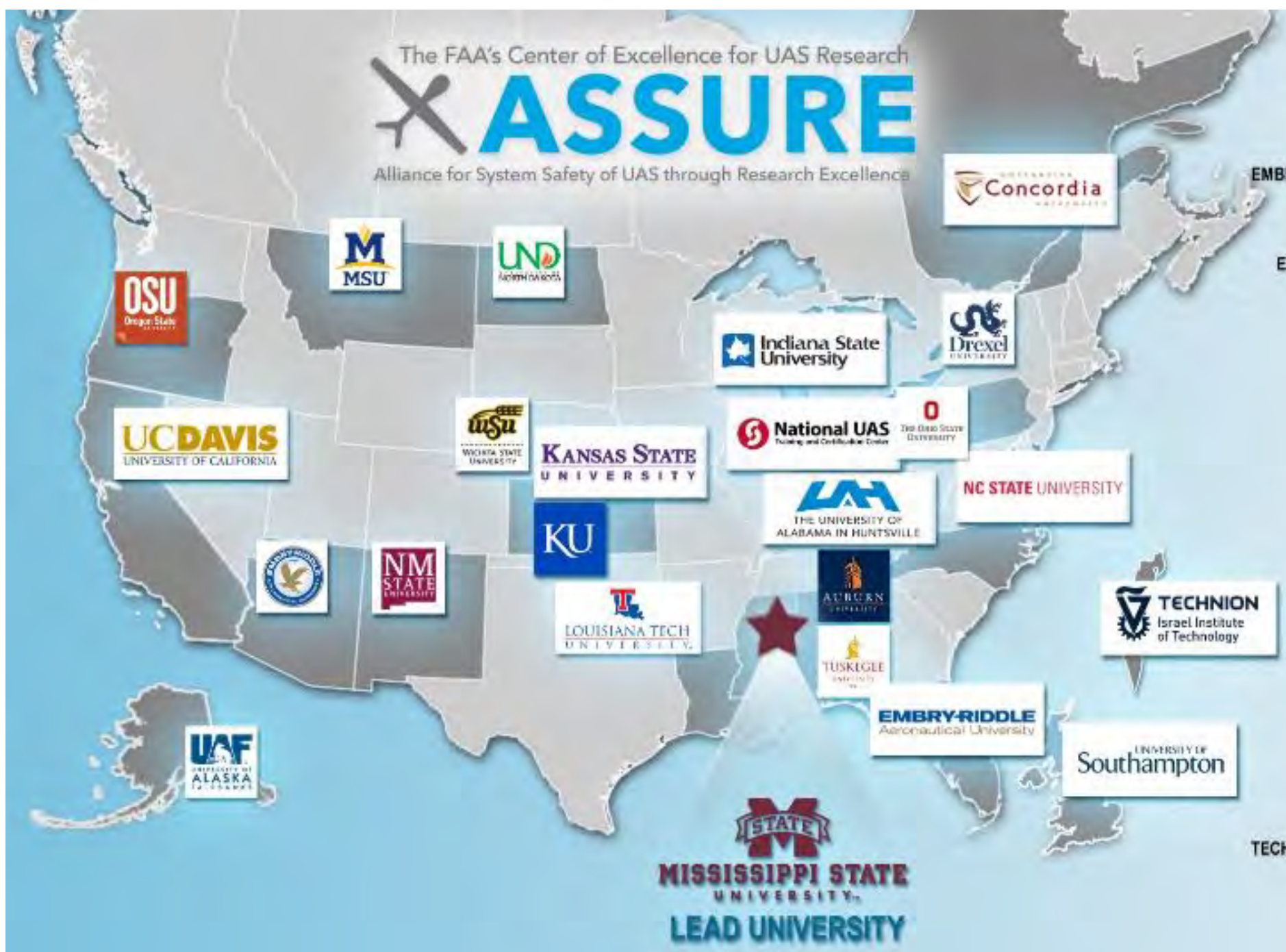
INDIANA STATE UNIVERSITY UNIVERSITY of ALABAMA in HUNTSVILLE UNIVERSITY of ALASKA in FAIRBANKS MBRY AERONAUTICAL UNIVERSITY.PRESCOTT UNINERSITY of CALIFORNIA DAVIS EMBRY RIDDLE AERONAUTICAL UNIVERSITY UNIVERSI TA STATE UNIVERSITY MONTANA STATE UR RITY NEW MEXICO STATE UNIVERSITY North Carolina NORTH CAROLINA STATE UNIVERSITY North Dakota UNIVERSITY OF NORTH DAKOTA OREGON STATE UNIVERSITY THE OHIO STATE UNIVERSITY

Pennsylvania DREXEL UNIVERSITY

AFFILIATE TEAM Alabama

AUBURN UNIVERSITY TUSKEGEE UNIVERSITY CHNION - ISRAEL INSTITUTE OF TECHNOLOGY Louisiana LA TECH UNIVERSITY SINCLAIR COMMUNITY COLLEGE Canada CONCORDIA UNIVERSITY United Kingdom
of SOUTHAMPTON UNIVERSTYY of SOUTHAMPTON 


\section{Certified Industry Partners}

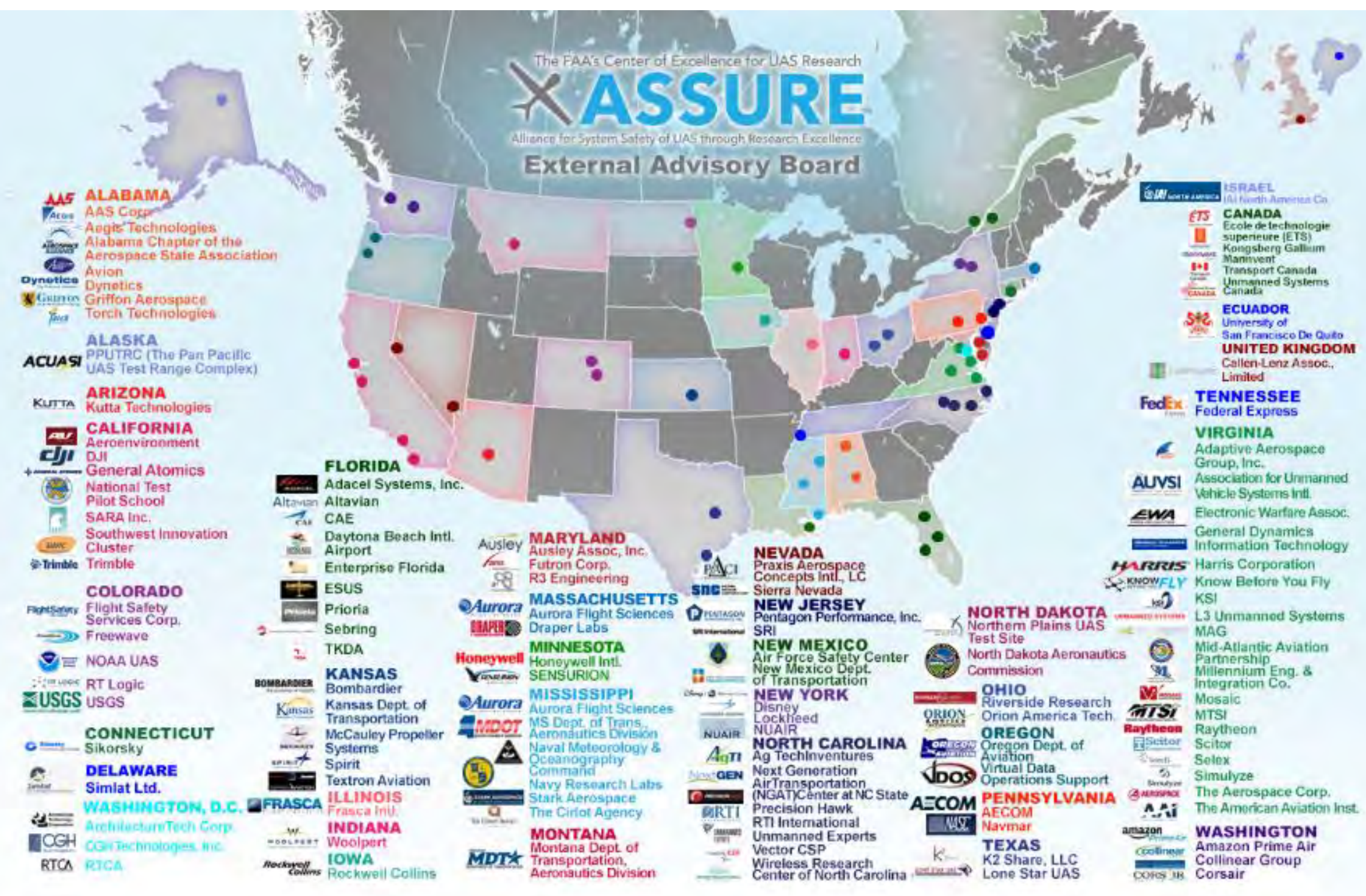




\section{Working with}

\section{ASSURE}

- Collaborate with ASSURE partners

- Join ASSURE Certified Partners team

- Annual Membership Fee (based on size of organization)

- Waivered for in-kind contributions to research reaching 10 times annual fee

- Participate \& influence research

- Public reports released by the FAA

- Non-certified partners are invited to public events

- ASSURE Research \& Development Corporation (ARDC)

- 501(c)3 Non-Profit - Solve problems / seek opportunities outside work for the FAA

- Leverages

- ASSURE Alliance and its relationships

- Knowledge and experience gained from FAA research 


\section{Project Title}

A1: Certification Test Case to Validate sUAS Industry Consensus Standards

A2: Small UAS Detect-and-Avoid (DAA) Requirements for Beyond-Visual-Line-of-Sight Operations (BVLOS)

A3: UAS Airborne Collision Severity Evaluation

A4: UAS Ground Collision Severity Evaluation*

A5: UAS Maintenance, Modification, Repair, Inspection, Training, and Certification *

A6: Surveillance Criticality Study *

A7: Human Factors Station Design Standards

A8: UAS Noise Certification

A9: Secure C2 \& Spectrum Management

A10: Human Factors UAS Control Station Certification and Procedures *

A11 Low Altitude Safety: Part 107 Waiver Request Study

A12 Detection of sUAS near Airports

UAS for STEM
MSState

OSU

MSU

NMSU

\section{Lead}

KSU

NMSU

WSU

UAH

KSU

NCSU

DU

ERAU

UAH

* Indicates ERAU participation 


\section{ERAU Technical Areas under ASSURE}

- ASSURE Executive Board Lead in

\section{Air Traffic Integration}

- Airport Ground Operations

- ATC Interoperability

- UAS Traffic Management

- Technical Co-Lead

- UA Pilot Training, Certification, and other UA Crew Training with KSU-Salinas

- Control and Communication (C2) with NCSU
- Supporting Research Areas

- Detect and Avoid (DAA)

- Human Factors

- Airworthiness

- Applications

- Low-altitude operations

- Noise Reduction and Wake mitigation

- Spectrum Management

- Economic Impact

- Outreach 


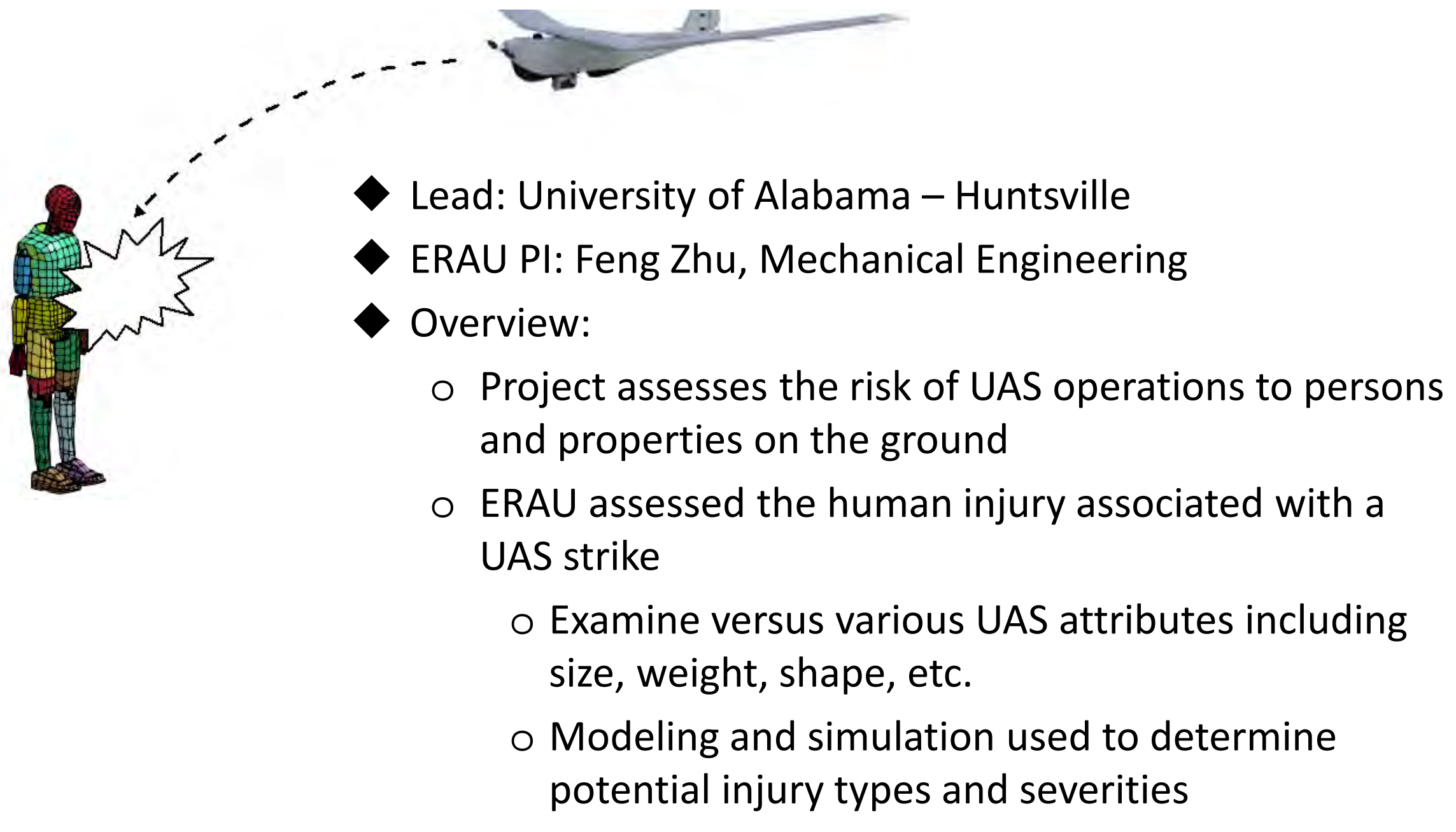


- 300 publications reviewed to evaluate existing injury metrics, battery standards, toy standards, and casualty models to determine applicability to small UAS

- Three dominant injury metrics applicable to sUAS

- Blunt force trauma injury - Most significant contributor to fatalities

- Lacerations - Blade guards required for flight over people

- Penetration injury - Hard to apply consistently as a standard

- Collision Dynamics of sUAS is not the same as being hit by a rock

- Multi-rotor UAS fall slower than metal debris of the same mass due to higher drag on the drone

- UAS are flexible during collision and retain significant energy during impact

- Wood and metal debris do not deform and transfer most of their energy

- Payloads can be more hazardous due to reduced drag and stiffer materials

- Blade guards are critical to safe flight over people

- Lithium Polymer Batteries need a unique standard suitable for sUAS to ensure safety 


\section{Comparison of Steel and Wood with Phantom 3}

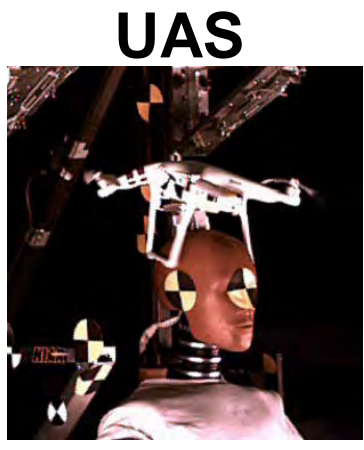

Test Weight: $2.69 \mathrm{lbs}$. Impact Velocity: 49-50 fps Impact Energy: 100-103 ft-lbs.

Motor Vehicle Standards

- Prob. of neck injury: $11-13 \%$

- Prob. of head injury: 0.01-0.03\%

\section{Range Commanders Council} Standards

- Probability of fatality from...

- Head impact: 98-99\%

- Chest impact: 98-99\%

- Body/limb impact: 54-57\%

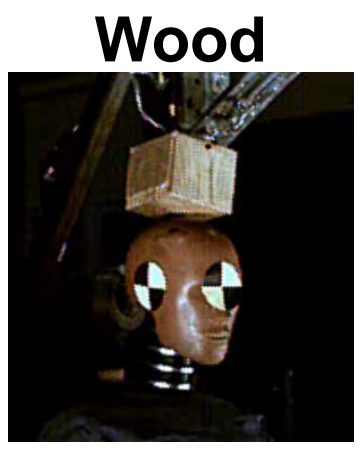

Test Weight: $2.69 \mathrm{lbs}$. Impact Velocity: 52-54 fps Impact Energy: 116-120 ft-lbs.

Motor Vehicle Standards

- Prob. of neck injury: 63-69\%

- Prob. of head injury: 99-100\%

\section{Range Commanders Council} Standards

- Probability of fatality from...

- Head impact: 99-100\%

- Chest impact: 99-100\%

- Body/limb impact: 67-70\%

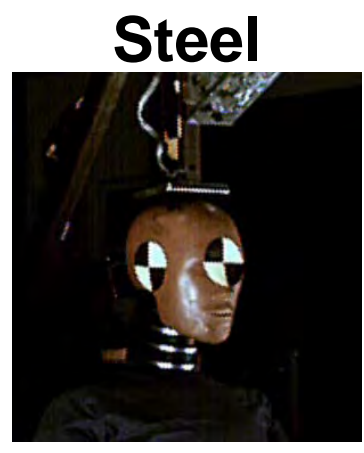

Test Weight: $2.7 \mathrm{lbs}$. Impact Velocity: 52-53 fps Impact Energy: 114-121 ft-lbs.

\section{Motor Vehicle Standards}

- Prob. of neck injury: $61-72 \%$

- Prob. of head injury: 99$100 \%$

Range Commanders Council Standards

- Probability of fatality from...

- Head impact: 99-100\%

- Chest impact: 99-100\%

- Body/limb impact: 65$71 \%$ 
A5 - UAS Maintenance,

Modification, Repair, Inspection, Training, and Certification Considerations

- Lead: Kansas State University - Salina

- ERAU PI: John Robbins, College of Aviation

- Overview:

- In-depth analysis of maintenance operations and considerations that different from manned aircraft

- Requirements for a maintenance program to ensure UAS remain airworthy

- Requirements for training of

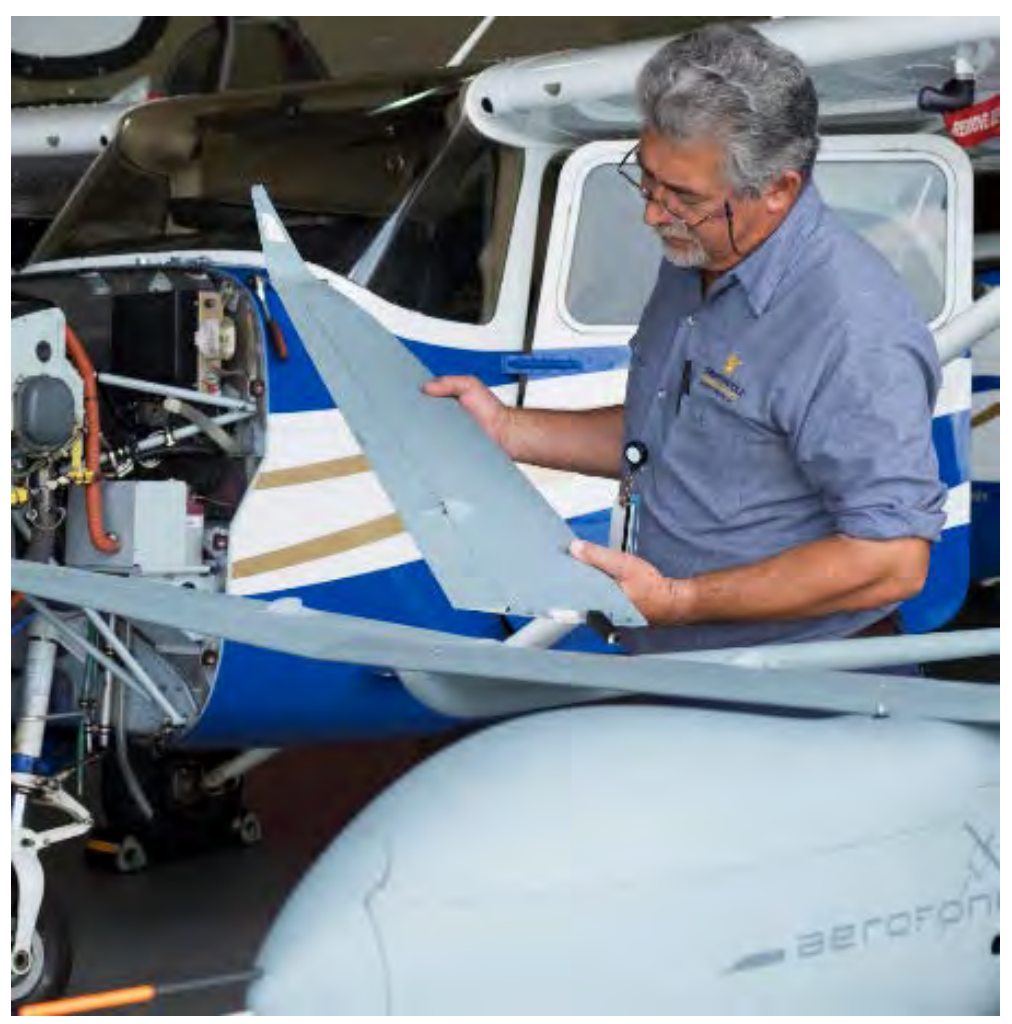
maintenance personnel

- Exploration of maintenance induced failures on the NAS

Final reports at ASSUREUAS.org 
Lead: North Carolina State University

$\checkmark$ ERAU PI: Mohammad Moallemi

- NEAR Lab

$\checkmark$ Overview:

- Examination of surveillance technologies for UAS detect-andavoid,

- Airborne RADAR, ADS-B, Ground-

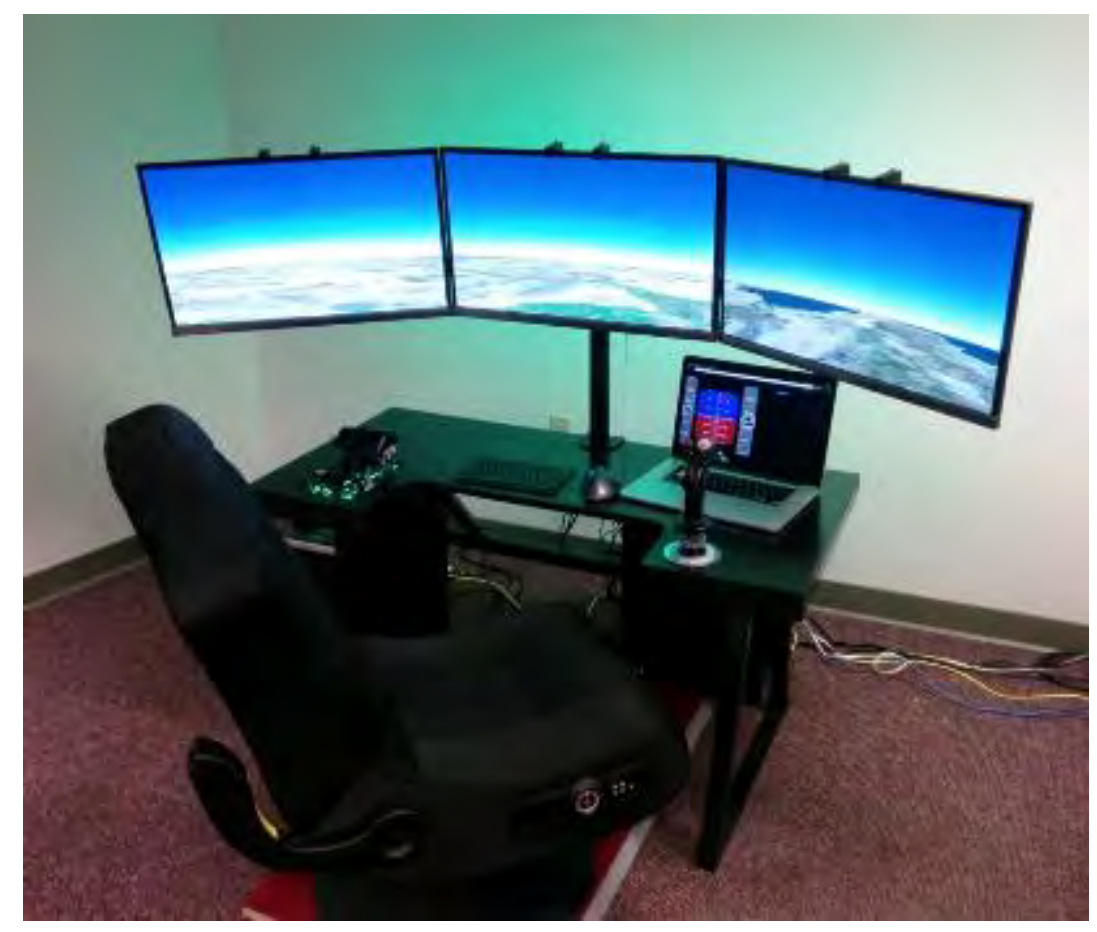
based RADAR, TCAS, etc.

- Determine the criticality of sensor(s) in ensure adequate separation of air traffic

- ERAU is supporting modeling and simulation

- Match $100 \%$ covered by Industry! 


\section{A10 - Human Factors Considerations \\ of UAS Procedures, \& Control Stations}

- Lead: ERAU

- Richard S. Stansbury (PI) and Joe Cerreta (technical lead)

- Overview:

- Addresses all phases of flight for larger than small fixed-wing UAS

- Address pilot and crew roles for: aviate, navigate, communicate, and contingency operations

- Three major components:

- Development of functional allocation and minimum control station requirements

- Develop minimum environmental and

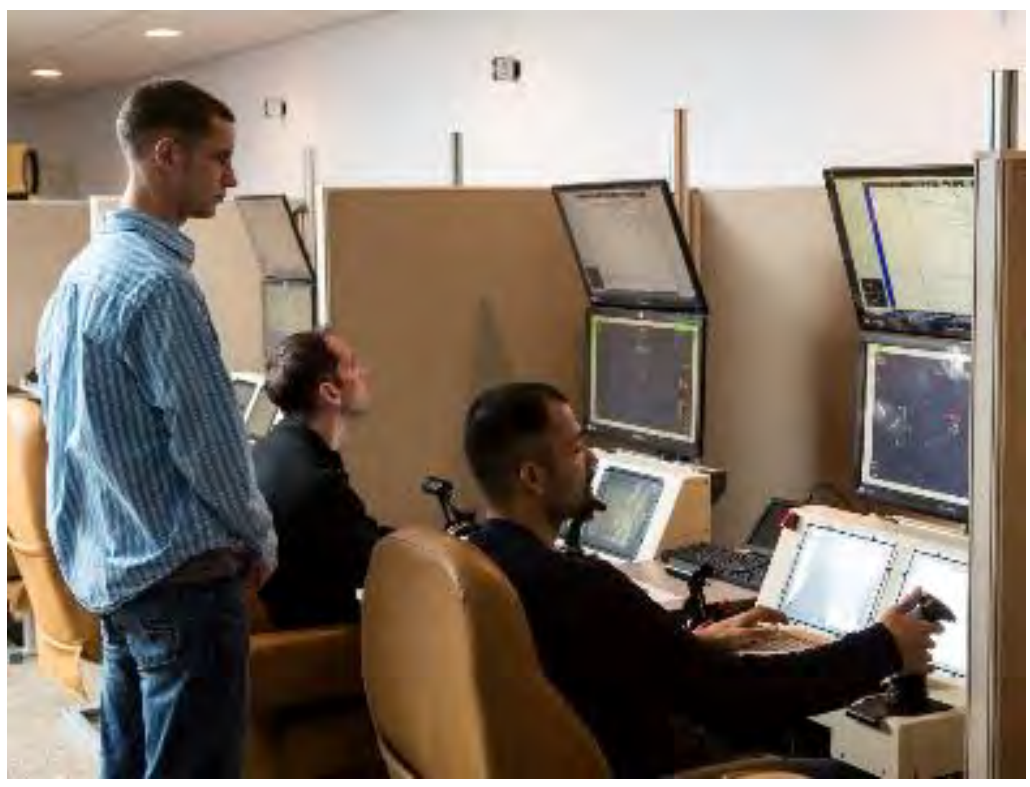
ergonomic requirements for UAS control stations

- Develop minimum pilot and crewmember procedures. 
- Partnership with Booz Allen Hamilton on ACRP 03-42 "UAS at Airports"

$>$ Development of guidance materials for stakeholders involved in operation at airports

D Stakeholders: UAS operators, airports, airport businesses, ATC, government (local, state, and federal), public, etc.

$>$ Kicked off March 2017, 18 month research project

$\square$ Deep learning-based terrain classification for emergency landing site detection

$>$ ERAU Internal Project

$\square$ Other Research Topics under Investigation:

$>$ UAS cybersecurity

$>$ Assured autonomy

$>$ Airport environment integration

$>$ UAS Air Traffic Management under FAA NextGen

$>$ Multi-sensor UAS detection, identification, and tracking

$>$ Vehicle health and recovery systems

$>$ UAS as a service architecture

$>$ Integrated modeling and simulation environments

$>$ Numerous others... 
UAS Integration is dependent upon education addressing operations, engineering, maintenance, and planning/logistics.
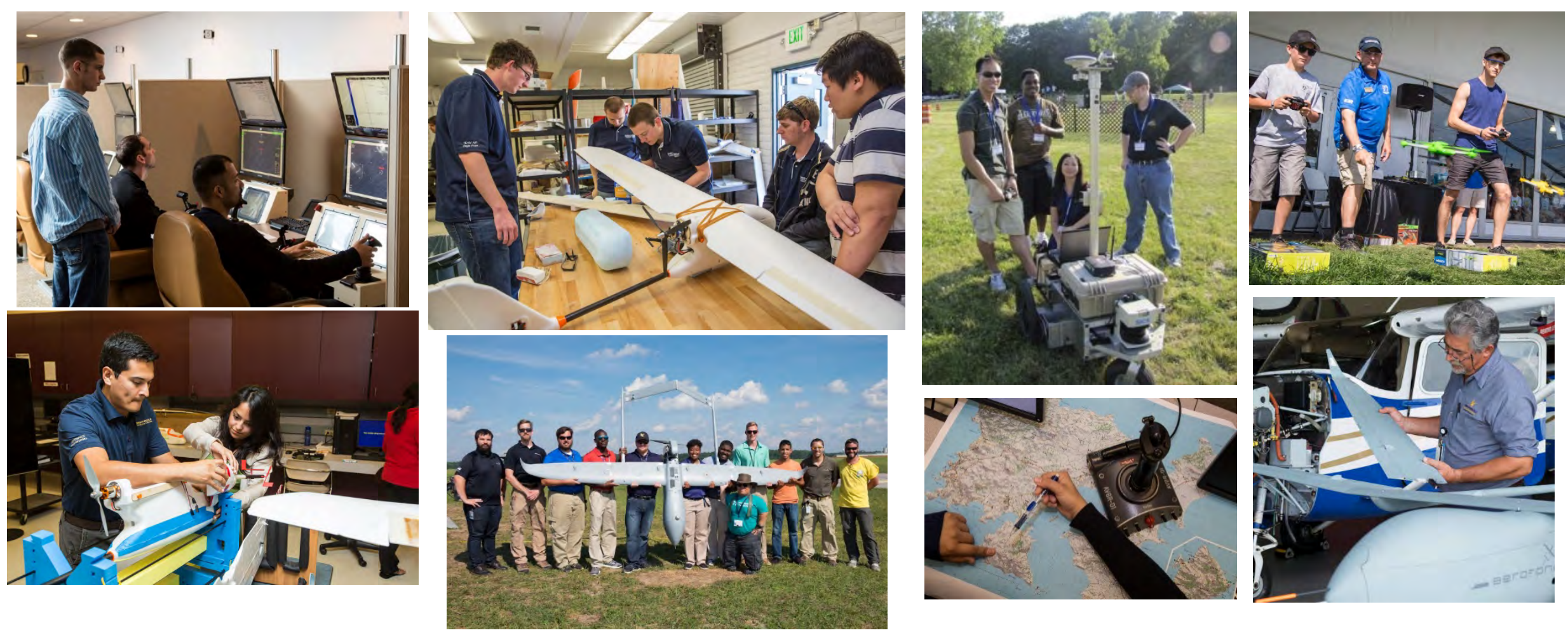


\section{UAS Integration is driven by applications.}
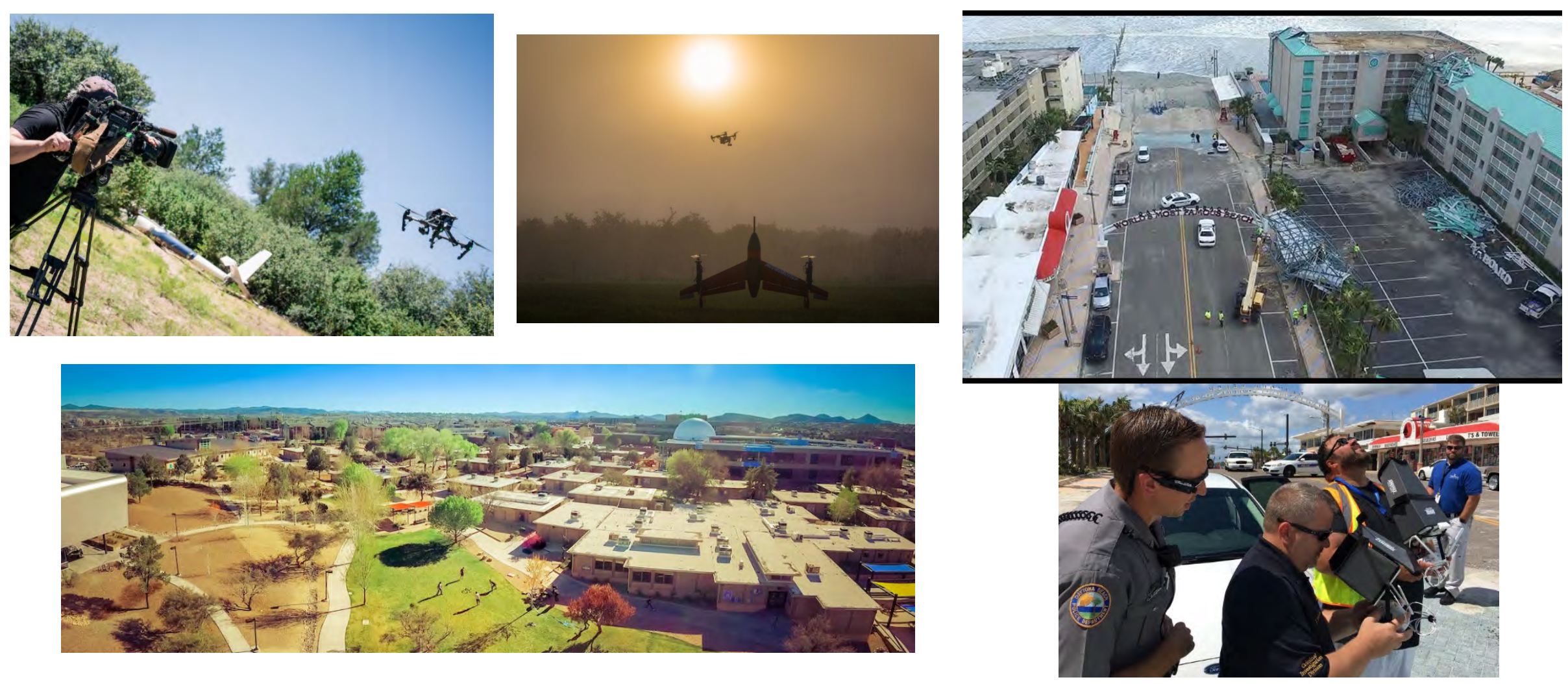


\section{UAS Integration is enabled by innovation.}
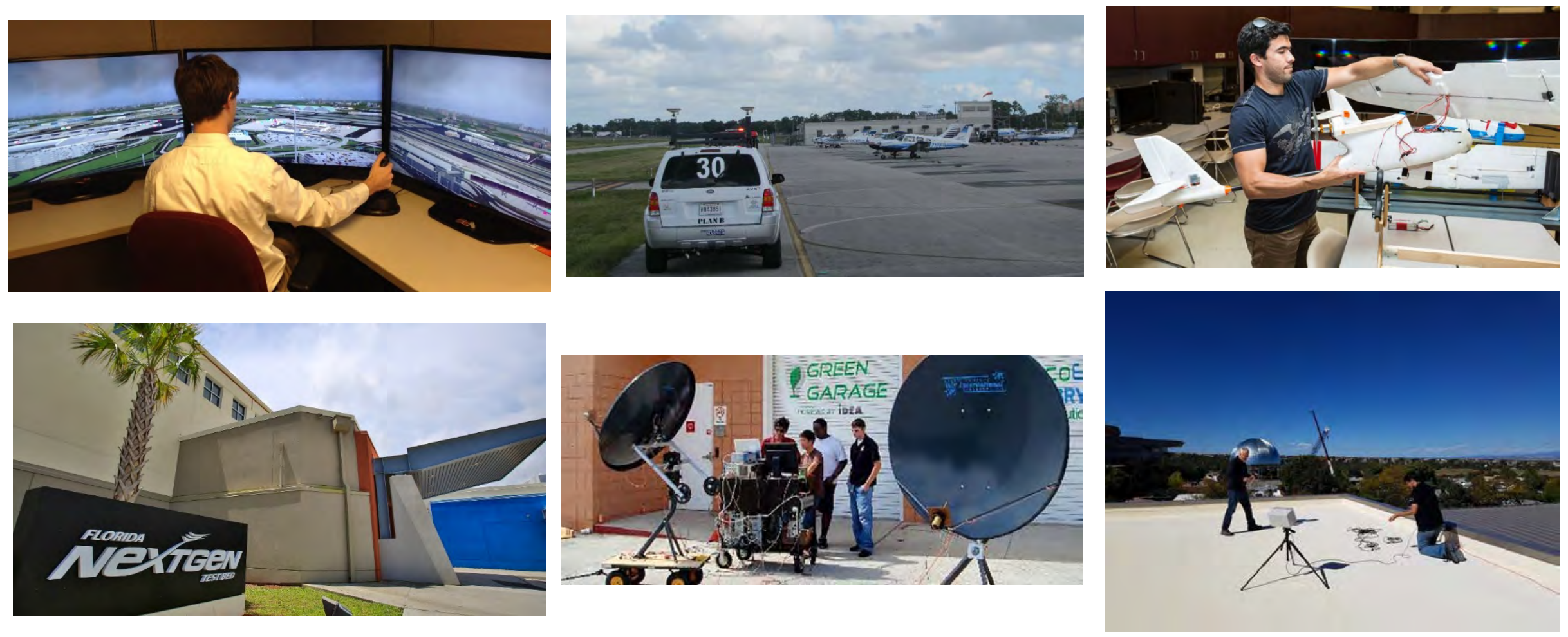


\section{Questions}
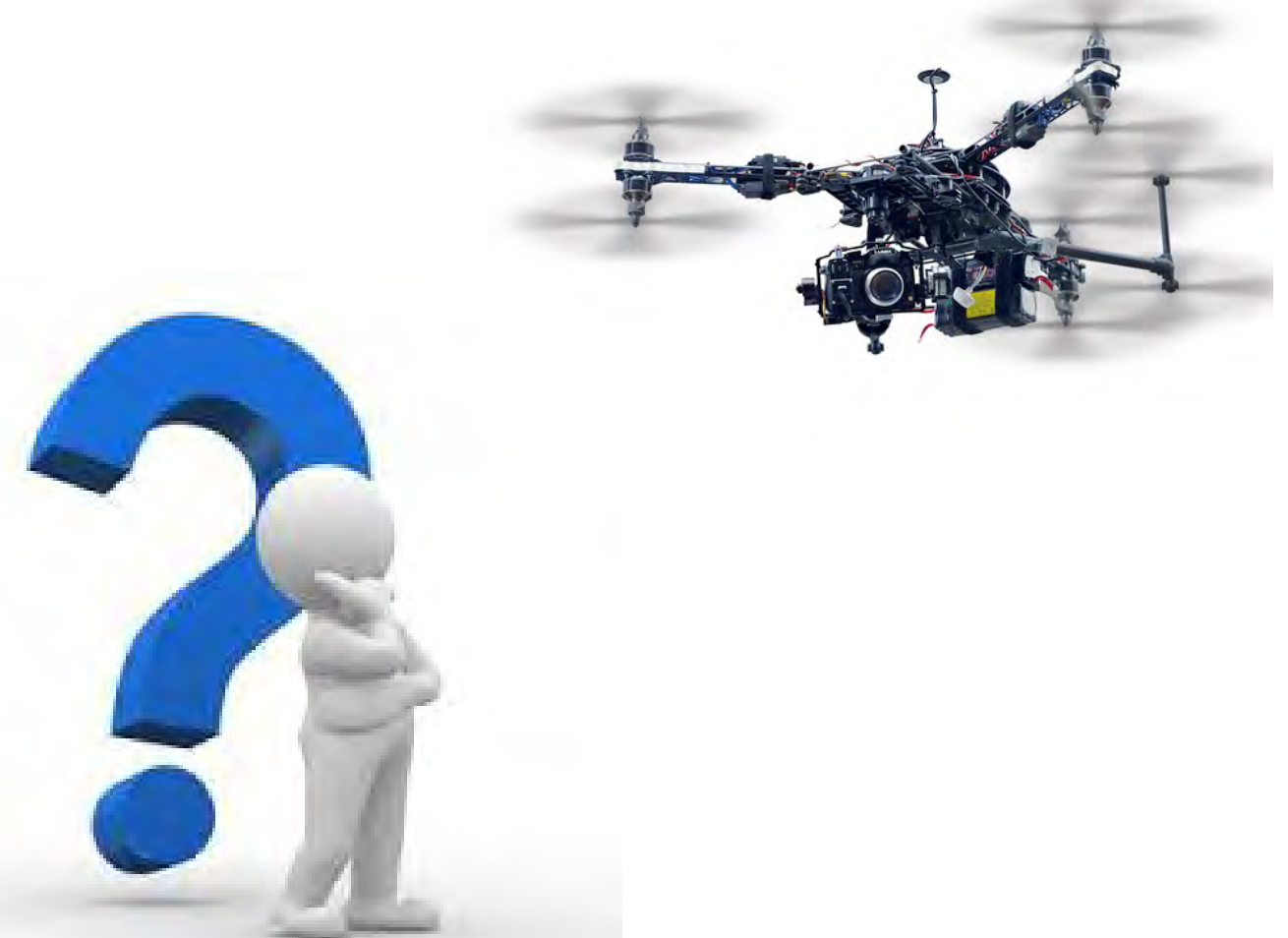